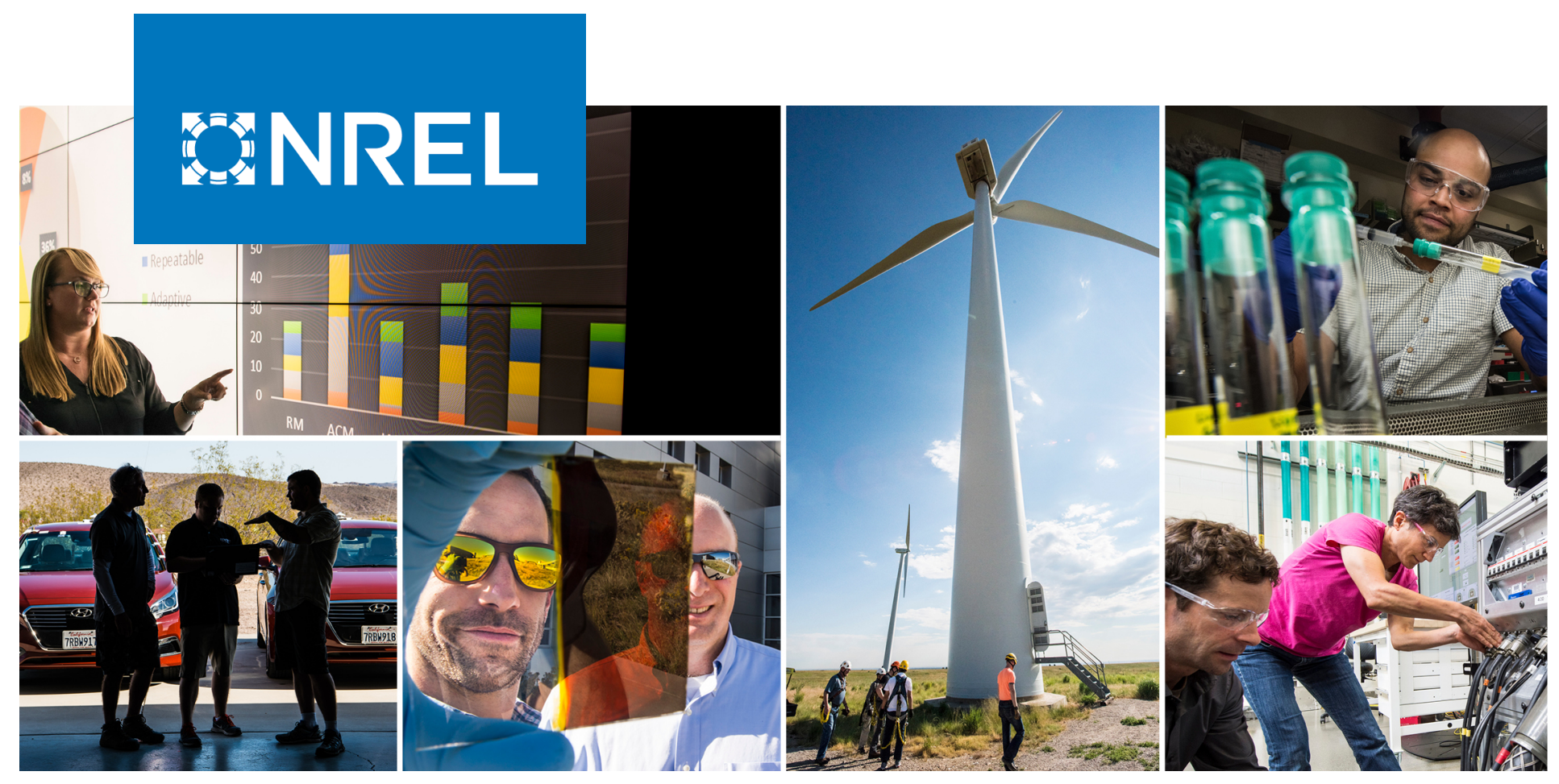

\title{
Cost Analysis Framework for Comparing $A C$ and DC Design Alternatives for Building Electrical Distribution Systems
}

Samantha Reese, ${ }^{1}$ Stephen Frank, ${ }^{1}$ Brian Ball, ${ }^{1}$ and Vagelis Vossos ${ }^{2}$

1 National Renewable Energy Laboratory 2 Lawrence Berkeley National Laboratory

NREL is a national laboratory of the U.S. Department of Energy Office of Energy Efficiency \& Renewable Energy

Operated by the Alliance for Sustainable Energy, LLC

This report is available at no cost from the National Renewable Energy Laboratory (NREL) at www.nrel.gov/publications.
Technical Report

NREL/TP-6A20-77732

May 2021 


\title{
BNREL
}

Cost Analysis Framework for Comparing $A C$ and DC Design Alternatives for Building Electrical Distribution Systems

Samantha Reese, ${ }^{1}$ Stephen Frank, ${ }^{1}$ Brian Ball, ${ }^{1}$ and Vagelis Vossos ${ }^{2}$

\author{
1 National Renewable Energy Laboratory \\ 2 Lawrence Berkeley National Laboratory
}

\section{Suggested Citation}

Reese, Samantha, Stephen Frank, Brian Ball, and Vagelis Vossos. 2021. Cost Analysis Framework for Comparing AC and DC Design Alternatives for Building Electrical Distribution Systems. Golden, CO: National Renewable Energy Laboratory. NREL/TP-6A20-77732. https://www.nrel.gov/docs/fy21osti/77732.pdf.

NREL is a national laboratory of the U.S. Department of Energy Office of Energy Efficiency \& Renewable Energy Operated by the Alliance for Sustainable Energy, LLC

This report is available at no cost from the National Renewable Energy Laboratory (NREL) at www.nrel.gov/publications.

Contract No. DE-AC36-08GO28308
Technical Report

NREL/TP-6A20-77732

May 2021

National Renewable Energy Laboratory 15013 Denver West Parkway Golden, CO 80401

303-275-3000 • www.nrel.gov 


\section{NOTICE}

This work was authored in part by the National Renewable Energy Laboratory, operated by Alliance for Sustainable Energy, LLC, for the U.S. Department of Energy (DOE) under Contract No. DE-AC36-08GO28308. Funding provided by the U.S. Department of Energy Office of Energy Efficiency and Renewable Energy Building Technologies Office. The views expressed herein do not necessarily represent the views of the DOE or the U.S. Government.

This report is available at no cost from the National Renewable Energy Laboratory (NREL) at www.nrel.gov/publications.

U.S. Department of Energy (DOE) reports produced after 1991 and a growing number of pre-1991 documents are available free via www.OSTI.gov.

Cover Photos by Dennis Schroeder: (clockwise, left to right) NREL 51934, NREL 45897, NREL 42160, NREL 45891, NREL 48097, NREL 46526.

NREL prints on paper that contains recycled content. 


\section{Acknowledgments}

The authors thank the members of the Energy Design and Scoping Tool for DC Distribution Systems project team for developing the underlying tools and expertise that led to this report. The authors especially thank Bern Gallagher and Sandy Vanderstoep of PVI Construction \& Maintenance for providing a practical industry perspective. The authors also thank Kim Trenbath, Omkar Ghatpande, and Larry Brackney for their valuable peer review comments that improved the quality of the manuscript.

This work was authored by the National Renewable Energy Laboratory, operated by Alliance for Sustainable Energy, LLC, for the U.S. Department of Energy (DOE) under Contract No. DEAC36-08GO28308 and by Lawrence Berkeley National Laboratory, operated for the DOE under Contract No. DE-AC02-05CH11231. Funding was provided by the DOE Assistant Secretary for Energy Efficiency and Renewable Energy Building Technologies Office Emerging Technologies Program. The views expressed in this report do not necessarily represent the views of the DOE or the U.S. Government. 


\section{List of Acronyms}

AC

CAIDI

DC

EERC

HPF

$\mathrm{kVA}$

LCC

LED

LOC

NPV

O\&M

OSAF

PV

PoE

SAM

SPP

SAIDI

SAIFI

URDB

VoLL alternating current

customer average interruption duration index

direct current

Energy Escalation Rate Calculator

harmonic power flow

kilovolt-ampere

life-cycle cost

light-emitting diode

lifetime operating cost

net present value

operation and maintenance

OpenStudio Analysis Framework

photovoltaic

power over Ethernet

System Advisor Model

simple payback period

system average interruption duration index

system average interruption frequency index

Utility Rate Database

value of lost load 


\section{Executive Summary}

In recent years, in response to the changing nature of building load, direct current (DC) distribution systems for buildings have been proposed as alternatives to traditional alternating current $(\mathrm{AC})$ systems. DC distribution offers a closer match to the types of loads and generation sources found in modern buildings, the majority of which use DC electricity internally either natively or as a power conditioning stage. The proposed benefits of DC distribution compared to AC distribution within buildings include higher efficiency, lower installation cost, lower operating cost, higher reliability, improved communication and control, and simplicity. Most recent DC distribution research has focused on quantifying the efficiency advantage of DC distribution over AC distribution. However, energy savings alone do not guarantee cost savings; a more complete cost accounting is required to establish financial benefit.

This report provides a framework for cost analysis and comparison of building electrical distribution systems, including common variants for both $\mathrm{AC}$ and $\mathrm{DC}$ distribution systems. The framework includes all major cost categories, including up-front costs (hardware, installation labor, soft costs, retrofit-specific costs) and long-term costs (energy, operations and maintenance); see Figure ES-1.

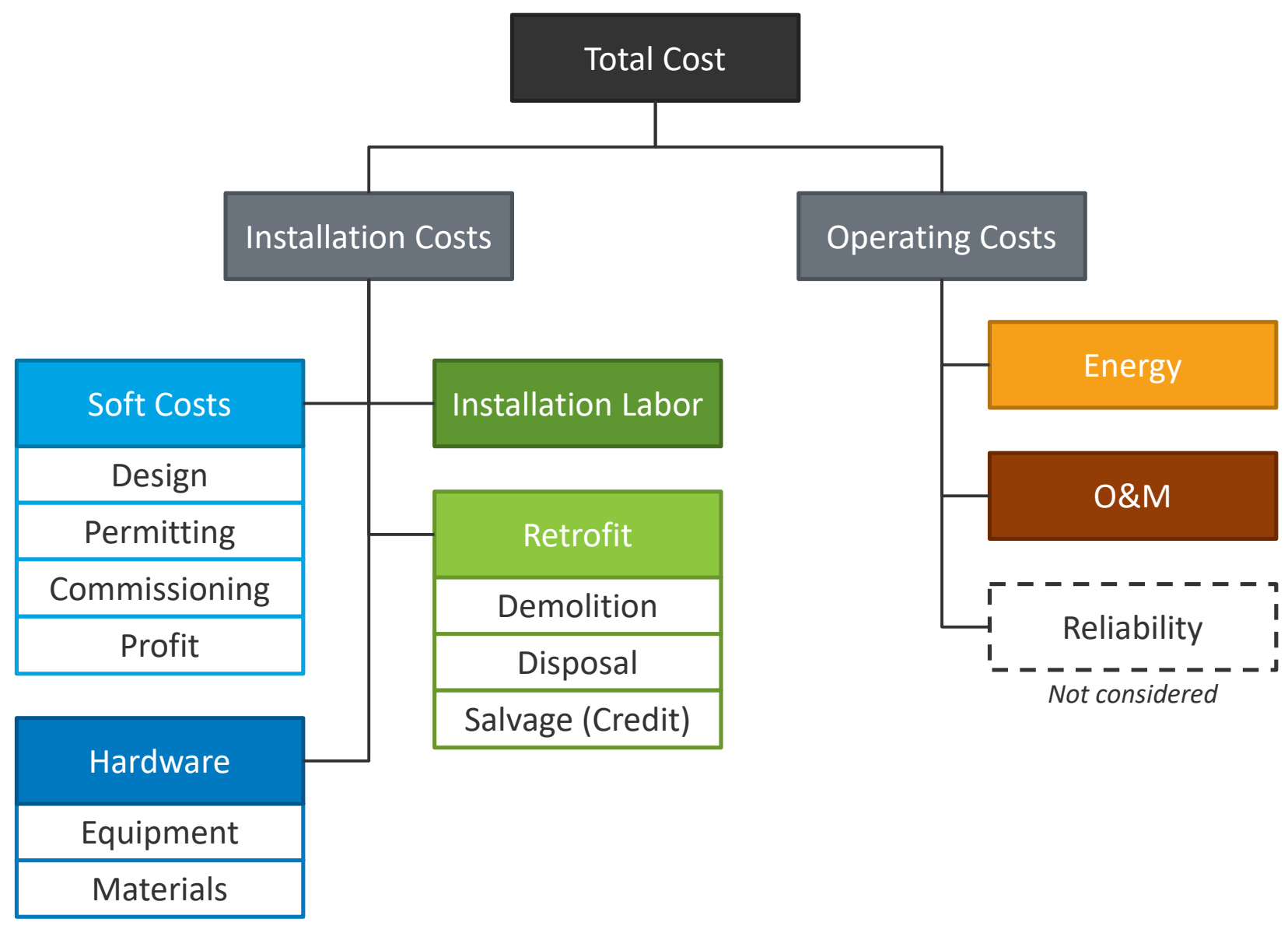

Figure ES-1. Cost categories and hierarchy for building electrical distribution systems 
The proposed cost model excludes costs and benefits associated with reliability because, at present, there is no accurate way to evaluate these costs in the context of building electrical distribution system design alternatives. However, the report discusses this capability gap in relation to recent research and proposes future work to address it. The proposed cost model also excludes financing and removal costs associated with project end of life. (Demolition, disposal, and salvage of existing systems in the context of retrofits is included.)

The report proposes standard formulas for calculating costs for each of the categories shown in Figure ES-1 and discusses sources of cost modeling data. The report also briefly defines and discusses three cost metrics often used to evaluate alternative designs: net present value, lifecycle cost, and simple payback period. Finally, the report provides a plan for integrating the proposed cost analysis framework into the OpenStudio ${ }^{\circledR}$ building energy analysis ecosystem.

While this report provides a framework for comparison of AC, DC, and hybrid distribution system design alternatives, it does not provide quantitative cost comparisons or draw conclusions about whether AC or DC distribution systems are more cost-effective. The authors recommend future research to refine the cost models presented in this report, develop high-quality quantitative cost estimates for the cost categories identified, and integrate the modeling approach into other building energy modeling tools such as OpenStudio. 


\section{Table of Contents}

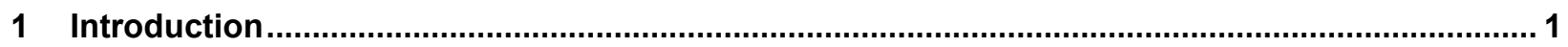

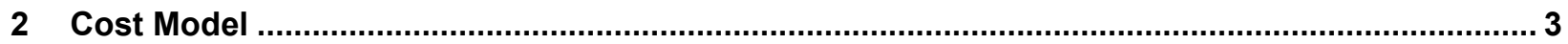

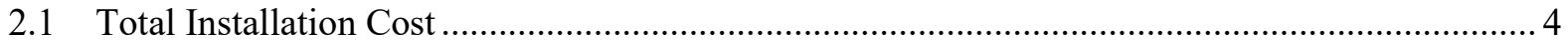

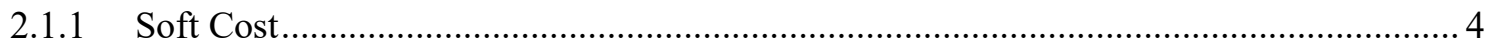

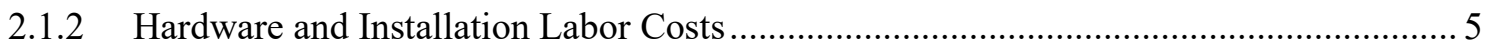

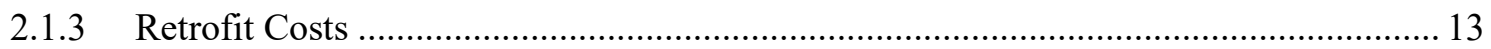

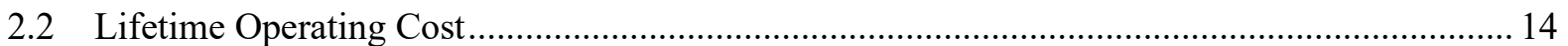

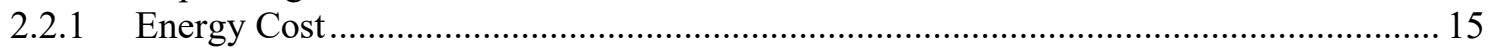

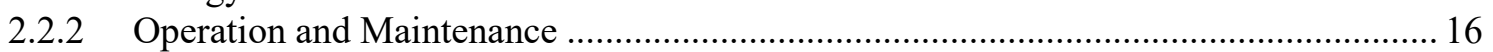

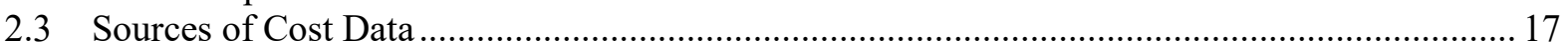

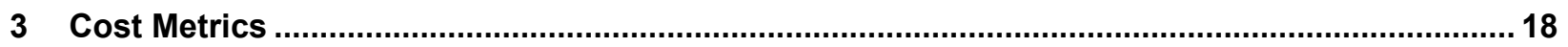

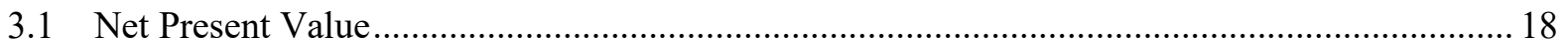

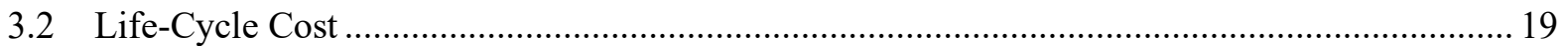

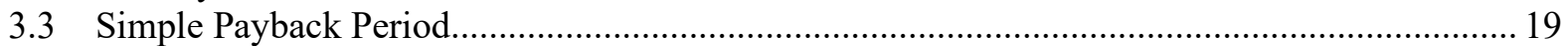

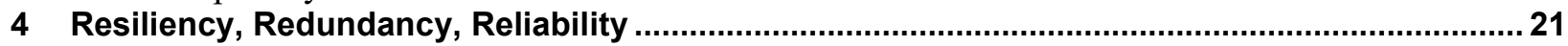

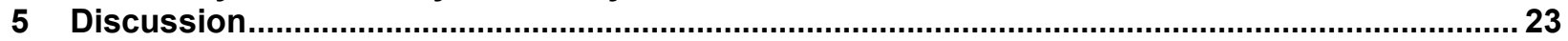

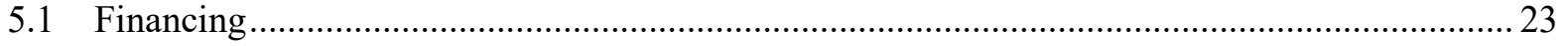

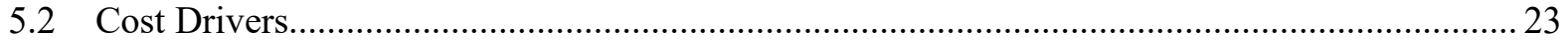

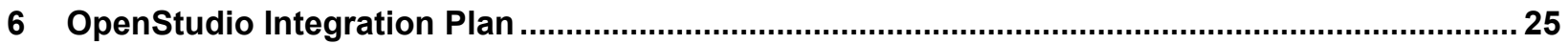

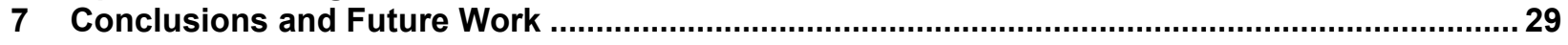

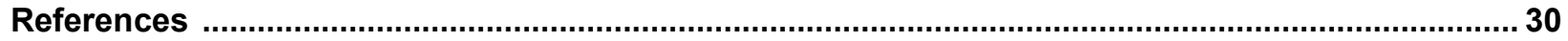

\section{List of Figures}

Figure ES-1. Cost categories and hierarchy for building electrical distribution systems .......................... v

Figure 1. Cost categories and hierarchy for building electrical distribution systems ................................ 3

Figure 2. Categories of hardware in building electrical distribution systems ....................................... 6

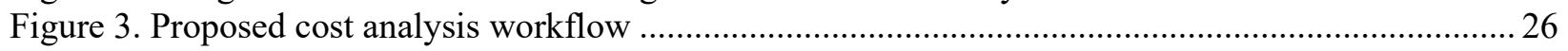

Figure 4. Co-simulation workflow for Energy Design and Scoping Tool for DC Distribution.................. 27

\section{List of Tables}

Table 1. Typical Hardware Cost Ranges for Example Electrical Distribution System Materials ............... 8

Table 2. Typical Installation Labor Cost Ranges for Example Installation Activities................................. 8 


\section{Introduction}

Traditional electricity distribution systems, including both utility networks and distribution within buildings, use alternating current (AC) electricity as the means of transferring electrical energy from sources to loads. However, a growing majority of building loads now use direct current (DC) electricity internally, either natively or as a power conditioning stage (George 2006; Savage, Nordhaus, and Jamieson 2010; Garbesi, Vossos, and Shen 2011; Marchionini and Zheng 2018). The same is true for distributed generation (primarily solar photovoltaic [PV] systems) and distributed energy storage assets installed on premises in commercial and residential buildings. In response to this changing mix of sources and loads, many researchers and organizations have proposed building-scale DC distribution systems or DC microgrids as alternatives to traditional AC systems (George 2006; Savage, Nordhaus, and Jamieson 2010; Boroyevich et al. 2010; Fregosi et al. 2015; International Electrotechnical Commission 2017; Gal et al. 2019; and many others).

The proposed benefits of DC distribution compared to AC distribution within buildings include higher efficiency, lower installation cost, lower operating cost, higher reliability, improved communication and control, and simplicity (see, for example, George 2006; Marchionini and Zheng 2018; Prabhala et al. 2018; Gal et al. 2019; Vossos et al. 2019). Much of the published literature focuses on efficiency comparisons between AC and DC distribution systems. Although savings estimates vary depending on system topology and other assumptions, recent studies have concluded that energy savings of 3\%-8\% are achievable for buildings without on-site PV and $5 \%-15 \%$ for buildings with PV, with higher savings possible if on-site battery storage is present (Vossos, Garbesi, and Shen 2014; Fregosi et al. 2015; Glasgo, Azevedo, and Hendrickson 2016; Gerber et al. 2018; Vossos et al. 2018; 2020).

However, efficiency gains by themselves do not guarantee financial savings when other system costs are considered. The cost modeling described in the existing literature to date is less robust than the efficiency modeling. Prabhala et al. (2018) provide a qualitative comparison of AC and DC distribution hardware and power converter costs for general use cases. Pratt, Kumar, and Aldridge (2007) and AlLee and Tschudi (2012) provide a similar discussion focused on DC data centers. They conclude that at $380 \mathrm{~V}_{\mathrm{DC}}$ the combination of lower converter costs (at scale), less copper, and energy savings make DC data centers less expensive than AC data centers. Sannino, Postiglione, and Bollen (2003) perform a general cost analysis for commercial DC distribution with battery backup using fixed cost assumptions. Thomas, Azevedo, and Morgan (2012); Glasgo, Azevedo, and Hendrickson (2016), and Vossos et al. (2018) propose stochastic, quantitative models for AC and DC distribution cost comparisons based on life-cycle cost (LCC) analysis. They apply their proposed models to several case studies using Monte-Carlo simulation: lighting for an office building in Pittsburgh, PA (Thomas, Azevedo, and Morgan 2012); residences in Austin, TX (Glasgo, Azevedo, and Hendrickson 2016); and several commercial building types in multiple climate zones (Vossos et al. 2018).

The cost analyses described above assume new construction and mostly focus on specific case studies and draw specific conclusions about the cost advantages (or disadvantages) of DC distribution systems based on fixed cost assumptions or cost distributions. Not all studies consider the same set of costs; Thomas, Azevedo, and Morgan (2012), for example, include cost 
comparisons for installation labor and operation and maintenance (O\&M) costs, but Glasgo, Azevedo, and Hendrickson (2016) do not. Nevertheless, most major cost categories (capital for hardware and materials, installation labor, energy, and O\&M) are covered by at least one publication. The "soft costs" of design, permitting, and the like are not well-addressed in the existing cost models, although Vossos et al. (2018) do provide a qualitative discussion of soft costs. Demolition and disposal costs or cost recovery (via salvage) are not addressed in the existing literature, nor does the literature explore cost differences between new construction and retrofits.

The purpose of this report is to provide a framework for cost analysis and comparison of building electrical distribution systems, including common variants for both AC and DC distribution systems. The goal is to provide a consistent approach for cost analysis and comparison for building electrical distribution systems that serves equally well for research case studies and practical design. A well-designed framework should have the following characteristics:

- Support all relevant costs, including up-front (capital, installation labor, soft costs) and long-term costs (energy, O\&M)

- Support both new construction and retrofit project analysis

- Support both forced replacement and unforced replacement scenarios

- Support future cost escalation (or de-escalation)

- Calculate standard cost metrics (LCC, payback period, return on investment, etc.)

- Facilitate cost comparison of distribution design alternatives

- Support sensitivity analysis and optimization.

This report synthesizes the prior work in these areas and, in particular, relies heavily on the comprehensive cost discussion provided by Vossos et al. (2018).

The remainder of the report is organized as follows: Section 2 describes the cost model and suggests data sources that may be used to populate it. Section 3 describes common cost analysis and comparison metrics in the context of the cost model. Section 4 specifically discusses reliability costs and why they are not captured in the proposed cost model, while Section 5 provides a more general discussion of considerations pertinent to cost modeling. Section 6 provides an integration plan for incorporating the proposed cost model and analysis framework into the OpenStudio ${ }^{\circledR}$ tool suite (OpenStudio Development Team 2020), for use with the Energy Design and Scoping Tool for DC Distribution Systems. ${ }^{1}$ Finally, Section 7 concludes the report and recommends future work. This report does not provide comprehensive cost data, provide quantitative or qualitative comparison of the cost of different distribution system designs, or draw conclusions about whether AC or DC distribution systems are more cost-effective. Rather, the goal of the report is to enable such analyses and comparisons by others.

\footnotetext{
${ }^{1}$ The Energy Design and Scoping Tool for DC Distribution Systems project was proposed to the Building Energy Efficiency Frontiers \& Innovation Technologies (BENEFIT) funding opportunity announcement (FOA) DE-FOA0001632 in 2017 and subsequently awarded under control number 1632-1575. A public summary of the project is available at https://www.energy.gov/eere/buildings/downloads/energy-design-and-scoping-tool-dc-distributionsystems.
} 


\section{Cost Model}

Cost metrics provide a measure of the economic value of an investment. Calculating cost metrics requires defining formulas for major costs and benefits. Figure 1 shows a basic cost model for building electrical distribution systems. Costs are divided into installation costs (up-front or onetime) and operating costs (ongoing). Subcategories of installation costs include installation labor, soft costs, hardware, and retrofit costs when applicable. Subcategories of operating costs include energy (utility) bills, O\&M, and reliability. Reliability costs are the costs to the building owner or operator of unplanned system outages or service disruptions. The proposed cost model acknowledges but does not attempt to quantify reliability costs/benefits (see Section 4). In addition, the proposed model omits financing costs and disposal costs (except for retrofits; see discussion in Section 2.1.3).

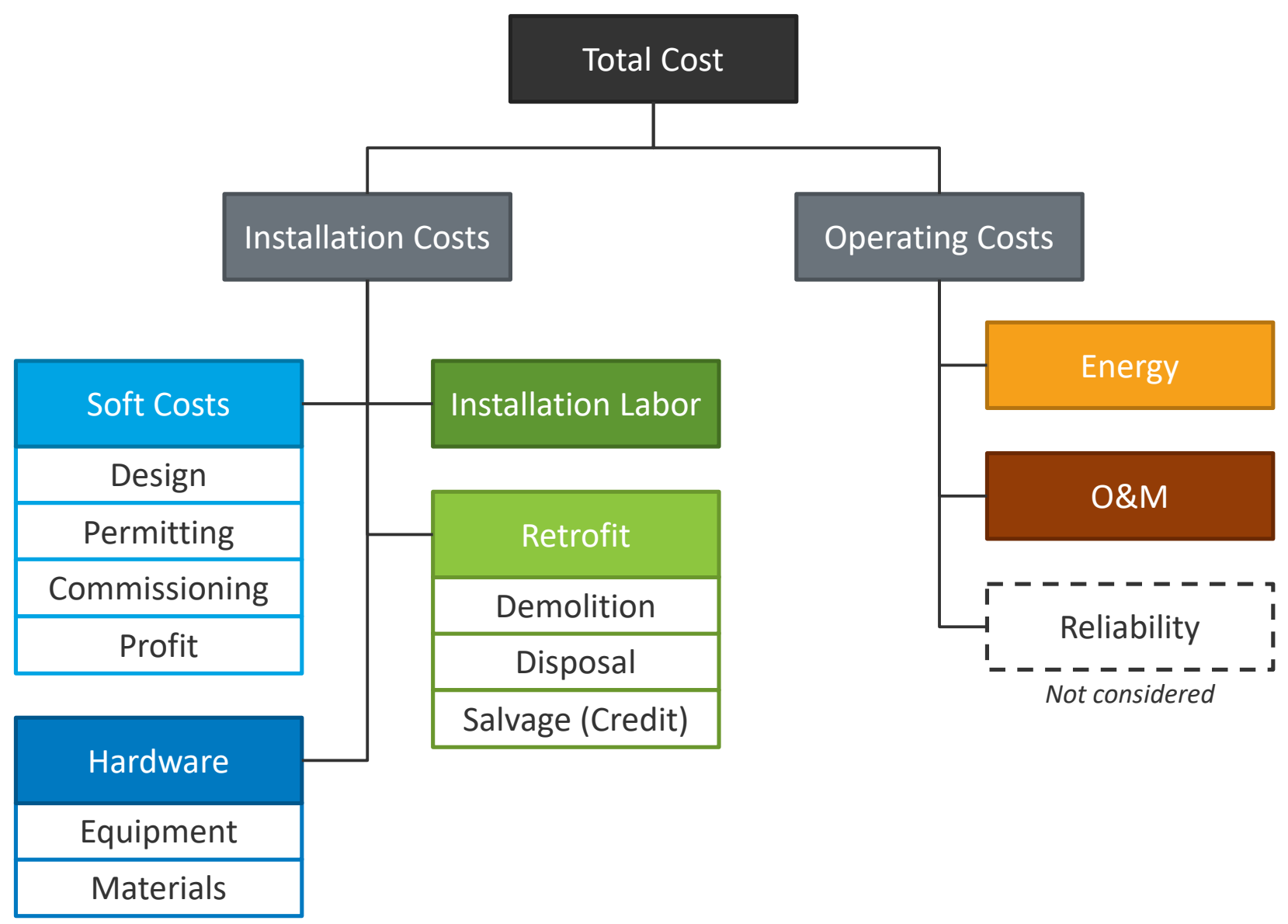

Figure 1. Cost categories and hierarchy for building electrical distribution systems

The proposed cost model encompasses both new construction and retrofits, but the "Retrofit" cost category applies only to retrofits. Specific costs may vary substantially between new construction and retrofit designs. To give one example, total labor for wiring may be substantially lower for new construction than for a retrofit (where demolition and mitigation of existing conditions must be considered). 
The remainder of this section provides formulas for specific cost types. The calculated values can then be used to calculate specific cost metrics (Section 3). When available from the literature, we provide approximate costs or cost ranges for specific cost categories, however, these estimates are illustrative rather than authoritative.

\subsection{Total Installation Cost}

The total installation cost for new construction is the sum of soft cost, hardware cost, and installation labor.

$$
\text { Total Installation Cost }=\text { Soft Cost }+ \text { Hardware Cost }+ \text { Installation Labor }
$$

For retrofits, demolition and disposal costs and salvage credits for the existing system must also be considered (see Section 2.1.3). The installation cost for a retrofit can be represented as:

Total Installation Cost

$$
=\text { Soft Cost }+ \text { Hardware Cost }+ \text { Installation Labor }+ \text { Retrofit Cost }
$$

\subsubsection{Soft Cost}

Soft costs are regional and system-dependent overhead costs related to design, permitting, commissioning, and profit margins. Design costs include architectural design, engineering, modeling, and drafting. Permitting costs include permitting fees and inspection costs.

Commissioning $(\mathrm{Cx})$ includes verification of system readiness and proper operation following installation. Other costs, such as insurance and legal fees, are not considered explicitly in the model, but may be lumped into design markup if desired.

$$
\text { Soft Cost }=\text { Design Cost }+ \text { Permitting Cost }+ \text { Cx Cost }+ \text { Profit }
$$

In the absence of project-specific information, design costs are often assumed to be a fraction of the total installation cost (in other words, applied as a cost multiplier). For example, design may be $10 \%-12 \%$ of total installation cost for new construction (Best and Meanley 1985; McGeorge 1988). For simplicity in calculation, the proposed cost model considers design cost as a fixed percentage (markup) of hardware and installation labor costs.

$$
\text { Design Cost }=\text { Design Markup } \times \sum(\text { Hardware Cost }+ \text { Installation Labor })
$$

Permitting costs are location-specific and may be affected by local policies and incentives. In many cases, permitting costs may also be estimated as a fixed fraction of installation hardware and labor costs. RSMeans data (RSMeans Data 2018) suggest the minimum permit cost will be $0.5 \%$ of the estimated project cost and as high as $2 \%$ of the estimated project cost.

$$
\text { Permitting Cost } \left.=\text { Permitting Markup } \times \sum \text { (Hardware Cost }+ \text { Installation Labor }\right)
$$

Cx costs vary according to the complexity of the distribution system. Cx costs may be higher for microgrids, managed DC distribution systems (such as Power-over-Ethernet [PoE]), and similarly complex system topologies. As with design and permitting costs, $\mathrm{Cx}$ costs may be 
estimated as a fixed percentage of hardware and installation labor. RSMeans (RSMeans Data 2018) does not provide Cx markup estimates by trade, however, whole building Cx markup is estimated at $0.25 \%-1.0 \%$. As a percentage of project cost, Cx costs specific to electrical distribution systems may be lower than Cx costs associated with other building systems such as building automation.

$$
\text { Cx Cost }=\text { Cx Markup } \times \sum(\text { Hardware Cost }+ \text { Installation Labor })
$$

Profit is a fixed percentage of total project cost (typically 10\%; cf. RSMeans Data 2018).

$$
\text { Profit } \left.=\text { Profit Margin } \times \sum \text { (Hardware Cost }+ \text { Installation Labor }\right)
$$

At present, it is often assumed that the design cost of DC distribution systems is high compared to traditional AC distribution due to low DC distribution penetration rates (Vossos et al. 2018). It is also likely that DC system permitting and commissioning costs are higher now than they will be in the future, again due to the lack of familiarity requiring additional review and system verification steps. However, reliable numerical data that quantify cost premium of DC design, permitting, and commissioning are not available. The expectation is that these cost differences will become negligible in the future when DC becomes a familiar design option.

Insights from the growth of the PV installation industry can inform the anticipated learning curve for DC distribution. According to an analysis of the literature by O'Shaughnessy et al. (2019), PV soft costs are lower for:

- Larger systems

- Systems installed during new construction

- Systems installed by experienced installers

- Systems installed in concentrated markets

- Systems installed in competitive markets and where customers receive more quotes

- Systems installed in markets with less onerous permitting requirements. ${ }^{2}$

These characteristics are all associated with technology maturation and growing deployment. Commercial PV soft costs dropped over 43\% between 2010 and 2018 (Fu, Feldman, and Margolis 2018) while commercial PV capacity grew by a factor of 33 (Solar Energy Industries Association and Wood Mackenzie 2020). Similarly, if DC distribution systems approach the penetration rates of AC systems, soft costs for DC distribution would also drop and are likely to approach parity with more traditional AC systems. This is true both for the industry as a whole and for individual design firms (Bern Gallagher and Sandra Vanderstoep 2020).

\subsubsection{Hardware and Installation Labor Costs}

Conceptually, hardware and installation labor are separate cost categories, but in practice they are estimated together. Installation labor is coupled with the selection of hardware being installed. Therefore, the proposed cost model discusses installation labor as a component of

\footnotetext{
${ }^{2}$ List adapted from O’Shaughnessy et al. (2019) with bullet organization for clarity.
} 
hardware costs. For reporting or for calculating, installation labor may be disaggregated from the hardware cost for each component.

Hardware costs (including associated installation labor costs) are calculated using bottom-up estimates of the cost contributions of each system component (including both equipment and material components). There are ten identified hardware component categories that contribute to the hardware installation cost: wiring/cabling, conduit, junction boxes, switches, receptacles, transformers, circuit breakers, electrical panels and switchgear, power electronic converters, and balance-of-system hardware for PV systems (Figure 2).

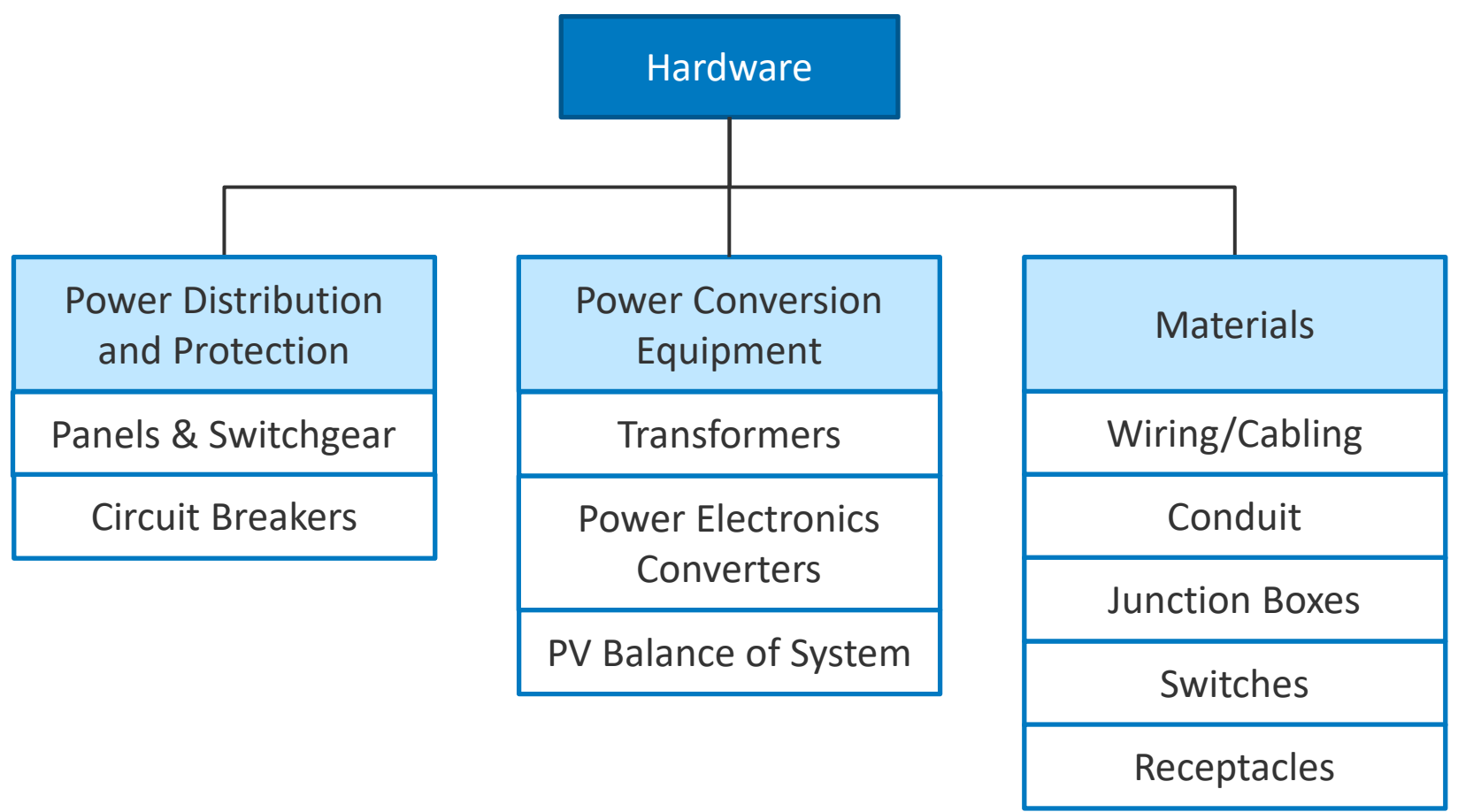

Figure 2. Categories of hardware in building electrical distribution systems

The cost of loads, generation sources (such as PV arrays), energy storage systems, and backup power systems (such as emergency generators or uninterruptable power supplies) is considered fixed among design alternatives and therefore excluded. However, we note that the power conversion stages immediately connected to such systems may differ among distribution designs and are therefore part of the cost model even if they are traditionally priced together with the rest of the system. The cost of auxiliary systems and components associated with electrical distribution (such as meters, sensors, and control devices) is also excluded, although we note that the cost of these auxiliary systems may be affected by the choice of AC vs. DC distribution.

Installation labor costs are dependent on geographical region, project size, and other details such as whether there are special considerations (e.g., for a government facility). The installation labor cost for many specific equipment types can be determined using information from RSMeans data (RSMeans Data 2018) and labor rate data from the U.S. Bureau of Labor Statistics Occupational Outlook Handbook (U.S. Bureau of Labor Statistics 2020). These costs include the appropriate overhead for the labor category. 


\subsubsection{Wiring and Cabling}

Wiring cost formulas are based on Waters et al. (2014); Thomas, Azevedo, and Morgan (2012); and Backhaus et al. (2015). The cost for wiring combines the cost of wire material and installation labor,

$$
\text { Wiring Cost }=\text { Wire Material }+ \text { Wiring Installation Labor }
$$

The cost for the wire material is the cost per unit length,

$$
\text { Wire Material }=\text { Total Length } \times \text { Unit Cost }
$$

Typical units are $\$ / \mathrm{ft}[\$ / \mathrm{m}]$ for the unit cost and $\mathrm{ft}[\mathrm{m}]$ for total length. ${ }^{3}$

The wiring installation labor can similarly be calculated as a function of wiring length,

$$
\begin{aligned}
& \text { Wiring Installation Labor } \\
& \qquad=\text { Total Length } \times \text { Labor per Unit Length } \times \text { Labor Unit Cost }
\end{aligned}
$$

Typical units are $\$$ /hour for labor unit cost and hours/hundred linear feet [hours/hundred meters] for labor per unit length. Labor unit cost differs by labor category (e.g., skilled vs. unskilled), which may be specific to each wire material.

Designs typically include multiple wire materials (e.g., multiple gauges, structures, or insulation types), each with an associated total length and installation cost. The total wiring cost is the sum of these individual wiring costs.

Differences in wiring cost between competing distribution designs may be significant because both wiring material and the associated installation labor may be case-specific. For example, low-voltage wiring, such as the Ethernet cable used for DC PoE applications, has a higher material cost than traditional wiring, but potentially a lower labor cost if skilled labor is not required for installation.

Wire material and labor costs vary with wire size and type. Large diameter wires have greater material and labor costs. Table 1 presents typical material cost ranges for several example materials; associated installation labor cost ranges. All costs are derived from RSMeans data (RSMeans Data 2018). Material costs for communication cable, such as Category 5e or 6 Ethernet cable, are higher.

\footnotetext{
${ }^{3}$ The data sources used throughout this report are most applicable to the United States and therefore the report uses units typical of the U.S. construction industry as the primary units.
} 
Table 1. Typical Hardware Cost Ranges for Example Electrical Distribution System Materials

\begin{tabular}{lcc}
\hline Material & Low & High \\
\hline Copper Wire (Solid) & $\$ 0.06 / \mathrm{ft}$ & $\$ 0.16 / \mathrm{ft}$ \\
& $(\$ 0.20 / \mathrm{m})$ & $(\$ 0.53 / \mathrm{m})$ \\
\hline Copper Wire (Stranded) & $\$ 0.08 / \mathrm{ft}$ & $\$ 0.13 / \mathrm{ft}$ \\
& $(\$ 0.26 / \mathrm{m})$ & $(\$ 0.43 / \mathrm{m})$ \\
\hline Conduit & $\$ 0.02 / \mathrm{ft}$ & $\$ 0.20 / \mathrm{ft}$ \\
& $(\$ 0.07 / \mathrm{m})$ & $(\$ 0.66 / \mathrm{m})$ \\
\hline Circuit Breaker (per breaker, by rated Amperes) & $\$ 6.60 / \mathrm{A}$ & $\$ 17.20 / \mathrm{A}$ \\
\hline
\end{tabular}

Table 2. Typical Installation Labor Cost Ranges for Example Installation Activities

\begin{tabular}{lcc}
\hline Labor Activity & Low & High \\
\hline Install Wiring & $\$ 0.37 / \mathrm{ft}$ & $\$ 1.20 / \mathrm{ft}$ \\
& $(\$ 0.20 / \mathrm{m})$ & $(\$ 0.53 / \mathrm{m})$ \\
\hline Install Conduit & $\$ 0.05 / \mathrm{ft}$ & $\$ 0.24 / \mathrm{ft}$ \\
& $(\$ 0.16 / \mathrm{m})$ & $(\$ 0.79 / \mathrm{m})$ \\
\hline Install Circuit Breaker (per breaker, by rated Amperes) & $\$ 1.25 / \mathrm{A}$ & $\$ 5.00 / \mathrm{A}$ \\
\hline
\end{tabular}

\subsubsection{Conduit}

Wire is typically installed in conduit, although this depends on the wire type, specifications, and application. Similar to wiring cost, the cost for conduit is equal to the conduit material and the installation labor.

$$
\text { Conduit Cost }=\text { Conduit Material }+ \text { Conduit Installation Labor }
$$

The cost for the conduit material is the cost per unit length.

$$
\text { Conduit Material }=\text { Total Length } \times \text { Unit Cost }
$$

Conduit unit cost is a function of required conduit size; conduit size and layout are a function of distribution system topology and code requirements.

Conduit installation labor is calculated as follows:

$$
\begin{aligned}
& \text { Conduit Installation Labor } \\
& \quad=\text { Total Length } \times \text { Labor per Unit Length } \times \text { Labor Unit Cost }
\end{aligned}
$$

If the specifics of conduit layout are not known, conduit costs may be lumped into wiring costs as an approximation. Conduit cost ranges are included in Table 1 and Table 2 in Section 2.1.2.1.

\subsubsection{Junction Boxes, Switches, and Receptacles}

Besides wiring and conduit, electrical distribution systems require other electrical materials including junction boxes, switches, and receptacles. Costs for such items are estimated per unit. 


$$
\begin{aligned}
& \text { Electrical Material Cost } \\
& =\sum_{\text {Item Type }} \text { (Item Quantity } \\
& \times(\text { Item Unit Cost }+(\text { Labor per Item } \times \text { Labor Rate }))
\end{aligned}
$$

Sources such as RSMeans (RSMeans Data 2018) provide unit hardware and labor estimates for many standard electrical material components. For example, installation of a standard pressed steel 4" box would cost $\$ 3.50$ to $\$ 5.20$ for the material and additional $\$ 24$ (with regional and project specific adjustments) in labor to install. For large projects, bulk discounts often apply.

Costs for some components may vary substantially between AC and DC distribution system designs. For example, standard $120 \mathrm{~V}_{\mathrm{AC}}$ receptacles (outlets) are commodity items available at very low cost. In contrast, because low-voltage DC receptacles are not yet standardized, they may require custom manufacturing at much higher unit cost. Exceptions do exist for certain DC system architectures. For example, PoE systems use commodity Ethernet cables, racks, and ports. Although USB components are also commodity items used in electronic device manufacturing, their use in distribution systems is not yet common.

The exact number of material components needed for an electrical distribution design is typically unknown during a project's design phase. Standard practice is to estimate quantities based on proxy measurements, such as estimating the required number of $120 \mathrm{~V}_{\mathrm{AC}}$ receptacles based on occupied floor area. Early in the design process, bulk cost estimates for materials (not differentiated by individual items) may be used. Due to these factors, there may be considerable uncertainty in material costs. Despite this uncertainty, it may be appropriate to neglect the costs for junction boxes, switches, and receptacles if two conditions are met:

1. The costs for these materials are expected to represent a small fraction of overall hardware cost.

2. The purpose of cost estimation is primarily to select among design alternatives (as opposed to budgeting for construction).

\subsubsection{Transformers}

AC distribution systems with multiple voltage levels typically include transformers to convert between voltage levels. Individual transformer cost is the sum of equipment and installation labor,

$$
\text { Transformer Cost }=\text { Transformer Equipment Cost }+ \text { Installation Labor Cost }
$$

Transformer equipment cost is a function of transformer power rating (Waters et al. 2014):

Transformer Equipment Cost

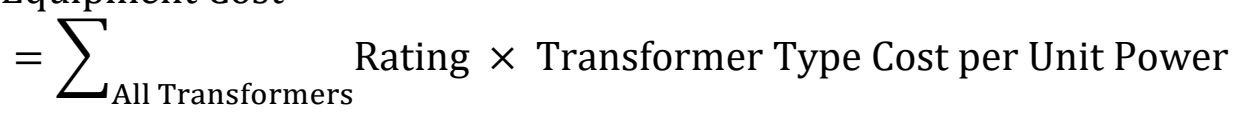

Transformer rating is specified in kVA (kilovolt-ampere) and cost per unit power rating is in $\$ / \mathrm{kVA}$. Within buildings, most transformers are categorized as either oil-filled or dry type. These 
distinct categories (types) of transformers have significantly different cost parameters. In addition, for each transformer type the cost per unit power may be fixed or may be a function of transformer size, such that larger transformers have a discounted cost per unit power. RSMeans data provide equipment costs on the order of $\sim \$ 400 / \mathrm{kVA}$ for dry-type transformers rated $\sim 1 \mathrm{kVA}$ reduced to $\sim \$ 25 / \mathrm{kVA}$ for oil-filled transformers rated $1,000 \mathrm{kVA}$ and above (RSMeans Data 2018).

Installation labor for large individual equipment such as transformers is typically specified as the number of labor hours required per transformer (Del Pico 2015),

$$
\begin{aligned}
& \text { Transformer Installation Labor Cost } \\
& =\sum_{\text {All Transformers }} \text { Labor per Transformer } \times \text { Labor Rate for Transformer Type }
\end{aligned}
$$

Again, labor hours and cost may both vary by transformer type and, potentially, as a function of transformer power rating.

In many cases, the utility-owned transformer is independent of the distribution system and can be excluded from the analysis. The transformer cost is then a function of the number and type of step-down transformers present in the building.

\subsubsection{Circuit Breakers}

Like transformers, circuit breakers are cost estimated by the unit (Del Pico 2015),

$$
\begin{aligned}
\text { Breaker Cost } & =\text { Breaker Quantity } \\
& \times(\text { Breaker Unit Cost }+(\text { Labor per Breaker } \times \text { Labor Rate }))
\end{aligned}
$$

Breaker unit costs and required labor may be functions of breaker rating (in Amperes [A]); in that case the equation becomes,

$$
\begin{aligned}
\text { Breaker Cost } & =\sum_{\text {Breaker Types }}(\text { Breaker Type Quantity } \\
& \times(\text { Breaker Unit Cost }+(\text { Labor per Breaker } \times \text { Labor Rate })))
\end{aligned}
$$

The number, type, and placement of circuit breakers in an electrical distribution system is a function of the system topology. In general, one circuit breaker is needed per distribution branch circuit. Current-limited circuits fed by power electronics converters are an exception; such circuits may not require any independent overcurrent protection. The output ports of PoE switches are one example. RSMeans data list breaker costs from $\sim \$ 17.2 / \mathrm{A}$ for a $600 \mathrm{~V}, 30 \mathrm{~A}$ breaker to $\sim \$ 6.60 / \mathrm{A}$ for a $600 \mathrm{~V}, 800 \mathrm{~A}$ breaker, plus an additional $\sim \$ 5 / \mathrm{A}$ to $\sim \$ 1.25 / \mathrm{A}$ (with regional and project specific adjustments) in labor to install (RSMeans Data 2018). RSMeans does not provide cost data for DC breakers.

If the circuit breaker quantity in distribution panels is not known, then it can be estimated based on the predicted system load (Vossos et al. 2018), 


$$
\text { Breaker Quantity }=\left\lceil\frac{\text { Total Load } \times \text { Oversize Factor }}{\text { Breaker Amperage } \times \text { System Nominal Voltage }}\right\rceil
$$

in which \lceil\rceil is the ceiling operator (indicating the result should be rounded up to the nearest whole integer). In effect, this equation represents an estimate of the parallel distribution circuits required to serve the load, where each circuit has an independent breaker. When total load equals connected load, a typical oversize factor is 1.25 . When total load represents peak demand (as available from a simulation tool such as EnergyPlus ${ }^{\circledR}$ (EnergyPlus Development Team 2020)), a larger oversize factor that accounts for the demand factor may be needed. Note that for threephase AC systems, this approximation of breaker quantity neglects breaker type and number of poles (e.g., 1-pole, 2-pole, or 3-pole). This equation may need to be applied multiple times for different load types under different assumptions about breaker amperage.

\subsubsection{Panels and Switchgear}

Electrical panels and switchgear are the hubs at which distribution branch circuits interconnect. Panel and switchgear configuration is specific to the system topology, while panel and switchgear type (specification) is a function of nominal distribution system type (AC or DC), voltage, and power levels. Panel requirements for a given topology may be determined by applying codes and standards, as is done in Waters et al. (2014). However, it is difficult to estimate general requirements or costs for panels and switchgears without access to topological details. If topological details are known, RSMeans may be used to obtain unit costs.

In general, panels are priced by the unit:

$$
\text { Panel Cost }=\sum_{\text {Panel Sizes }} \text { Panel \# by Size } \times(\text { Panel Cost }+ \text { Installation Labor Cost })
$$

in which

$$
\text { Panel Installation Labor Cost }=\text { Labor per Panel } \times \text { Labor Rate }
$$

where panel hardware cost and labor per panel are both a function of discrete panel size or type. Typically, panel size is a function of power rating and number of circuits. (Switchgear and switchboard costs use the same formulas, with "switchgear" substituted for "panel.") Grounding and internal wiring are assumed to be part of panel and switchgear installation costs.

\subsubsection{Power Electronics Converters}

Power electronics converters are used throughout both AC and DC distribution systems. Common converter categories include:

- Load-packaged rectifiers (AC/DC converters) for electronics, internal or external

- Lighting ballasts (for fluorescent lighting) and drivers (for light-emitting diode [LED] lighting)

- PV system inverters (DC/AC converters)

- Variable frequency drives (VFDs) for motors

- Battery-connected inverter/chargers (AC/DC bidirectional converters) 
- Large AC/DC and DC/DC converters for grid interconnection or voltage conversion in $\mathrm{DC}$ and hybrid (mixed AC-DC) distribution systems

- $\mathrm{DC} / \mathrm{DC}$ converters for DC-connected electronic loads

- DC optimizers for PV systems.

Estimating hardware costs per individual converter is inefficient, especially when many converters of diverse (and potentially unknown) size may be present. Instead, hardware costs for converters may be estimated in the aggregate for each converter category either by total connected load,

Converter Equipment Cost $=$ Connected Converter Load $\times$ Converter Cost per Unit Power

or by total number of estimated converters based on an average converter size,

$$
\text { Converter Equipment Cost }=\left\lceil\frac{\text { Connected Converter Load }}{\text { Typical Converter Size }}\right\rceil \times \text { Converter Unit Cost }
$$

These calculations may be performed for each category of converter based on the system(s) served. Converter cost (or converter cost per unit power) may be fixed or a function of converter size; in the latter case the calculation must be performed for a mix or distribution of converter sizes anticipated to be present in the system. Converter costs also vary with converter complexity, including whether the converter includes power factor correction (PFC). PFC is required by standards on large converters, but small converters (such as power supplies for charging portable electronics) are often exempt. In the existing literature, converter cost parameters are often sampled from distributions derived from sales literature and internet vendor sources (Glasgo, Azevedo, and Hendrickson 2016; Vossos et al. 2018).

Total converter cost also includes installation labor. For load-packaged converters, installation costs may be assumed to be included as part of the procurement and general installation process for the load devices, and therefore neglected. For converters that are procured integral with other systems (e.g., drives for motors, inverters for PV systems), installation costs may be assumed to be part of the labor associated with installing the broader system. In cases where the installation labor is associated with installing the broader system, those installation labor costs may be neglected regardless of distribution system design. However, for large converters that form an integral part of the distribution network, such as DC/DC converters that provide low-voltage DC voltage, installation costs should be estimated on a per-converter basis, similar to costing for transformers, breakers, panels, and switchgear,

$$
\text { Converter Installation Labor Cost }=\text { Labor per Converter } \times \text { Labor Rate }
$$

For large numbers of similar converters, bulk percentage discounts may optionally be applied (Del Pico 2015, 145).

\subsubsection{Balance of System for PV Installations}

"Balance of system" components for PV systems are a special case of power electronics converter cost modeling. PV system design can differ significantly for AC and DC distribution 
systems. AC-connected PV systems use central inverters or microinverters to convert DC electricity generated by the PV array to AC electricity suitable for use on the electric grid. In contrast, DC-connected PV systems may be directly connected to a DC distribution bus or may use highly efficient maximum power point tracking DC optimizers to connect the PV array to a DC bus. (DC optimizers are also sometimes used to boost power output in systems with conventional, centralized AC/DC converters.)

When comparing PV system integration costs between AC and DC distribution design alternatives, the modeler must make appropriate design substitutions for the converters present in the system. Converter costs may then be calculated per Section 2.1.2.7. Alternatively, a detailed PV modeling tool such as the System Advisor Model (Freeman et al. 2018) may be used to calculate installation costs for AC- and DC-connected system design alternatives. Dedicated design tools are especially helpful if PV system size will change in response to increased distribution system efficiency, if (for example) the PV system is designed to offset a fixed percentage of total building energy consumption.

\subsubsection{Retrofit Costs}

Costs (and cost avoidance) associated with demolition, disposal, and salvage activities may be considered at two times: at a project's end of life (end of evaluation period for life cycle costing accounting) or at the beginning of a retrofit project (to account for removal of existing equipment). The proposed cost model does not consider demolition, disposal, and salvage costs associated with project end of life for three reasons:

1. Future costs are typically discounted in cost comparison metrics (see Section 3), making end-of-life costs small in comparison to other costs.

2. Forecasting cost specifics for demolition, disposal, and salvage many years in the future is highly uncertain.

3. Demolition and disposal activities tend to be similar for AC and DC distribution systems, such that cost differences among alternative designs are likely to be negligible. Therefore, evaluating these costs does not provide a differentiator among system options.

On the other hand, demolition, disposal, and salvage may need to be considered when evaluating proposed retrofits. For retrofits, any costs associated with removing existing distribution systems increase the total installation costs. The importance of capturing these costs is situational.

- For complete retrofits, in which the entirety of the existing system must be removed, the net cost associated with demolition, disposal, and salvage for the existing system will be identical for all design alternatives. Therefore, these costs are not a differentiator and can be neglected.

- For partial retrofits, only a portion of the existing system may be replaced and the specific portion to be replaced may differ among the design alternatives. (For example, a DC distribution retrofit may require rewiring a large portion of the building, while a conventional AC retrofit may be able to reuse existing wiring.) As a result, the net cost for demolition, disposal, and salvage may also differ among the design alternatives and therefore should be calculated for comparison. 
- In the case of an unforced retrofit, in which the net value of the proposed design(s) is being compared to a baseline of taking no action, it is also important to include removal costs for the existing system.

For a retrofit construction project, the costs associated with removal of an existing system can be represented as:

$$
\text { Retrofit Cost }=\text { Demolition Cost }+ \text { Disposal Cost }- \text { Salvage Value }
$$

The demolition cost is represented as:

$$
\text { Demolition Cost }=\sum_{\text {All Components }} \text { Component Removal }
$$

The cost for removing each type of component can be represented as:

$$
\text { Component Removal }=\text { Component Quanity } \times \text { Unit Removal Cost }
$$

For some components (e.g., wiring), removal costs may be per unit length or per unit weight rather than per unit. Component removal costs may be estimated using RSMeans data or from experience with similar projects. The cost of disposal may be included in the component removal cost, or may be estimated separately (e.g., by volume or weight for general or specialty construction waste).

Salvage provides cost recovery via sale of removed components. For electrical distribution systems, salvage is typically limited to selling copper from demolished wiring. (Although electrical panels and other components may contain other metals such as steel, a literature search and an interview with a domain expert revealed no instances in which these were given salvage value.) Salvage value is typically calculated by weight:

$$
\text { Salvage Value }=\text { Material Weight } \times \text { Unit Value }
$$

RSMeans sets the value of reclaimed copper wire at approximately $\$ 1.60 / \mathrm{lb}[\$ 3.53 / \mathrm{kg}]$ (RSMeans Data 2018). Even considering price volatility in the copper market, the salvage value for recovered copper will be insignificant compared to the overall project cost. For example, $1000 \mathrm{ft}$ [304.8 m] of 14-AWG copper wire would have an estimated salvage value of only \$19.84 (RSMeans Data 2018). Current construction practice is either to abandon existing wiring in place or to fully remove it; in the case of full removal the salvage may cover the cost of the removal but no more (Bern Gallagher and Sandra Vanderstoep 2020).

\subsection{Lifetime Operating Cost}

Lifetime operating costs (LOC) consist of the sum of all costs associated with keeping the distribution system operational that are incurred after system installation. The LOC can be represented by,

$$
\text { LOC }=\text { Total Energy Cost }+ \text { Lifetime O\&M Cost }
$$

Operating costs can also be reported annualized, which is required for many cost metrics. 


\subsubsection{Energy Cost}

Calculating energy cost first requires predicting (typically, simulating) the energy consumption for each distribution system alternative using an electrical network efficiency model (e.g., Fregosi et al. 2015; Gerber et al. 2018; Santos et al. 2019). The energy consumption data may then be postprocessed using a tariff tool, such as those available in EnergyPlus (EnergyPlus Development Team 2020), System Advisor Model (Freeman et al. 2018), or REopt ${ }^{\mathrm{TM}}$ (NREL 2020). In the United States, the OpenEI Utility Rate Database (OpenEI 2020) provides a variety of standard utility rates (tariffs) that tariff tools can use to predict energy costs.

The system boundary is a key consideration when comparing the energy efficiency (and therefore energy cost) of two or more building electrical distribution system design alternatives. It is important to distinguish energy savings associated with the distribution system from energy savings associated with selection of alternative types of loads (e.g., substitution of LED lighting for fluorescent lighting). An "apples-to-apples" comparison of distribution systems requires that each system service identical loads and sources.

Bernal et al. (2021) propose standard system boundaries for the analysis and comparison of building electrical distribution system design alternatives. The selection of system boundary affects which devices are considered within the scope of the energy efficiency comparison. Bernal et al. (2021) describe the following possible system boundaries:

1. Whole-building boundary: all systems, equipment, and loads downstream of the electric utility point of common coupling (PCC). ${ }^{4}$ This boundary includes loads. It is suitable for calculating and comparing overall energy use, but not for identifying energy efficiency associated with the electrical distribution system only.

2. Distribution network boundary: the electrical distribution system between the utility PCC and the interface with end-use loads. This boundary includes conversion equipment associated with the electrical network and with distributed energy resources, but it does not include load-packaged power converters. This boundary allows direct comparison of distribution system performance without load efficiency as a confounding factor.

3. Distribution network boundary plus primary conversion stages: this system boundary includes all equipment within the electrical distribution network plus the primary stages of power converters packaged with each load. (For example, it would include the external AC/DC power supply for a laptop computer, but not the laptop itself.) Load-packaged converters are included because their efficiency is impacted by the choice of distribution system. Including them within the system boundary allows co-optimization of the total efficiency of the distribution network and the converters serving the loads.

4. End-use load boundary, including effective load and conversion stages: This boundary analyzes the energy efficiency of individual load categories, including the efficiency of the primary stages of their power converters. It allows an abstract analysis of the optimal power delivery characteristics for loads (e.g., AC vs. DC, voltage level) distinct from the performance of the distribution network.

\footnotetext{
${ }^{4}$ The PCC is typically the location of the utility meter.
} 
For cost analysis and comparison of building electrical distribution design alternatives, the distribution network boundary, with or without the primary stages of load-packaged converters, is the most appropriate for cost comparison. If load-packaged converters are included in the efficiency analysis, they should also be considered in the cost analysis. For more discussion, see Bernal et al. (2021).

The energy cost is the cost over the lifetime of operation. Energy costs change over time. It is important to take this into account when determining the lifetime energy cost. If the tariff engine used to compute energy costs does not support energy cost escalation, the Energy Escalation Rate Calculator (EERC) (Federal Energy Management Program 2020) can be used as an alternative. The EERC provides multipliers to scale first year energy cost to future years and to lifetime energy cost,

$$
\text { Year } 1 \text { Energy Cost }=\text { Energy Cost from Tariff Engine }
$$

$$
\text { Year } y \text { Energy Cost }=\text { Energy Cost from Tariff Engine } \times \text { EERC Multiplier }
$$

For grid-connected distribution systems (which represent the vast majority of building electrical distribution systems), electricity consumption from the electric grid is likely to differ among considered distribution system design alternatives. Associated electricity costs will therefore also differ based on the building's utility rate structure.

\subsubsection{Operation and Maintenance}

O\&M costs encompass ongoing non-energy (non-fuel) costs. Maintenance cost represents labor and material costs "required to keep a system in operation" (Short, Packey, and Holt 1995). These are typically scheduled operations that do not result in significant service interruptions. Regular equipment inspections are an example of maintenance costs. Repair costs are typically repairs (unplanned) and replacements (planned or unplanned). Replacement of a failed circuit breaker is an example of a repair cost.

Predicting O\&M cost precisely is difficult and requires knowledge of anticipated equipment replacement schedules. While estimating equipment replacement can be done, a simpler and generally accepted estimation method for O\&M is that it will be approximately equal to a small fraction of the system's initial capital cost each year, e.g., 1\%-2\% (Short, Packey, and Holt 1995):

$$
\begin{gathered}
\text { Annual O\&M Cost }=\text { Total Installed System Cost } \times \text { O\&M Multiplier } \\
\text { Lifetime O\&M Cost }=\text { Annual O\&M Cost } \times \text { System Lifetime }
\end{gathered}
$$

The expected O\&M multiplier is expressed as a fraction (e.g., 0.01 for $1 \%$ ). Typically, O\&M costs are not escalated with time (see, for example, Biolek and Hanák 2019).

Well-designed DC distribution systems can be simpler than AC systems, which would theoretically decrease O\&M costs (Bern Gallagher and Sandra Vanderstoep 2020). However, DC systems O\&M cost reductions have not yet been proven because the technology is nascent. As research quantifies the reliability of DC systems, it may be warranted to modify the maintenance 
multiplier for DC systems compared to AC systems. This is a recommended topic for future research.

\subsection{Sources of Cost Data}

Sources of cost data include the following:

- Installation: The largest source of cost estimation data for building construction is the RSMeans data set (RSMeans Data 2018), which is updated annually. Secondary publications that leverage RSMeans data, such as Del Pico (2015), can be used to inform cost formulas and determine labor hour estimates for equipment installations. RSMeans is typically accurate for standard practice (AC installations) but contains little data applicable to novel designs (including DC installations). Instead, case studies from DC pilot projects (see Vossos et al. 2020) can inform installation cost estimates for DC distribution systems.

- Hardware: Codes and standards can provide sizing information and minimum power requirements for many components, such as wiring and conduit.

Researchers have also leveraged data from scraped vendor websites to determine typical cost ranges for power electronics converters and other equipment (Glasgo, Azevedo, and Hendrickson 2016; Vossos et al. 2018).

- Labor: In addition to RSMeans, wage or salary databases such as the Occupational Outlook Handbook (U.S. Bureau of Labor Statistics 2020) may be used to obtain or calibrate labor rates.

- Energy: Utility rate data is available from the Utility Rate Database (OpenEI 2020) and from individual electric utilities' public disclosures. 


\section{Cost Metrics}

Three of the most widely reported and useful metrics to evaluate the economics of design are net present value (NPV), LCC, and simple payback period (SPP). In this section, we describe these three metrics and provide formulas for calculating them. Other metrics found in the literature but not described here include internal rate of return, modified internal rate of return, net savings, discounted payback period, benefit-to-cost ratio, and savings-to-investment ratio (Short, Packey, and Holt 1995; Schade 2007). Bernal et al. (2021) discuss several of these metrics in the context of evaluating DC distribution system designs.

\subsection{Net Present Value}

NPV is the aggregate value of all cash flows associated with a project calculated with respect to a base year, which is usually the present year (Short, Packey, and Holt 1995). Typically, if NPV is positive, the investment is deemed worthwhile (Law and Smullen 2008). The advantage of using NPV is that it takes into account the time value of money; it ensures that at minimum the market rate of interest is earned (Flanagan et al. 1989). An unforced replacement project (e.g. an energy efficiency upgrade) might use NPV in the traditional sense if cost savings are treated as revenue. However, achieving a positive NPV for an unforced replacement of electrical distribution equipment is difficult.

When comparing design alternatives for a project, such as alternative building electrical distribution system designs (whether new construction or forced retrofit), NPV must be considered differently than when it is used for an investment that has revenue generation potential. NPV is still valuable because it accounts for the time value of money; however, generally NPV will be not be positive for any design alternative. Therefore, the goal is to select the design with smallest negative value (least net present cost).

NPV is typically expressed as:

$$
\mathrm{NPV}=\sum_{y=0}^{N} \frac{F_{y}}{(1+r)^{y}}
$$

in which:

- $F_{y}$ is net cash flow in year $y$

- $\quad N$ is the analysis period in years

- $\mathrm{r}$ is the annual discount rate.

Year 0 is the beginning of the analysis period. Year 1 is the end of the first year of operation. The first year of operation's cash flow is discounted in the NPV method.

In the case of cost modeling for a building electrical distribution system, the net cash flow will always be negative. $F_{y}$ is related to the cost model presented in Section 2 as follows: 


$$
\begin{gathered}
F_{0}=-(\text { Total Installation Cost }) \\
F_{y}=-(\text { Year } y \text { Energy Cost }+ \text { Annual 0\&M Cost })
\end{gathered}
$$

The system that had the higher NPV (least negative) would still be considered the better investment (lowest cost system considering the time value of money). A significant disadvantage to NPV is that it is not usable when there are different life lengths for the competing technologies (Kishk et al. 2003). Further discussion of NPV can be found in Short, Packey, and Holt (1995).

\subsection{Life-Cycle Cost}

The LCC of a system is the total installation cost plus the LOC. LCC incorporates all costs during the system lifetime; however, it does not include any positive cash flows, i.e., revenues (Short, Packey, and Holt 1995).

The LCC can be represented as,

$$
\text { LCC }=\text { Total Installation Cost }+ \text { LOC }
$$

The LOC can be represented as,

$$
\text { LOC }=\sum_{y=1}^{N} \frac{\text { Operating } \operatorname{Costs}(y)}{(1+r)^{y}}
$$

in which

- $r$ is the annual discount rate

- $y$ is the year

- $\quad N$ is the analysis period (system lifetime) in years.

LOC consists of energy and O\&M costs; see Section 2.2. For comparing design alternatives, LCC for both alternatives would be calculated. The design with the smallest LCC is the preferred option.

LCC can theoretically be calculated with an additional variable that takes into disposal costs and salvage value at end of project life. However, the proposed cost model neglects these costs (see Section 2.1.3).

\subsection{Simple Payback Period}

Simple payback period (SPP) is the amount of time required for a project's (non-discounted) net cash flow (i.e., savings or revenue) to equal or exceed the (also non-discounted) initial cost (Short, Packey, and Holt 1995; Vossos et al. 2018). In simple terms, SPP calculates the time required to return the initial investment. When comparing investments, whichever investment has the shortest payback time is deemed the most profitable one (Flanagan et al. 1989). When 
evaluating a single investment, if the payback time is shorter than an acceptance threshold, the investment is accepted.

SPP can be expressed as (Ferreira et al. 2015):

$$
\mathrm{SPP}=\frac{\text { Initial Investment }(\$)}{\text { Annual Savings (\$/year) }}
$$

However, the cost model of Section 2 does not define annual savings. Therefore, to compare distribution system design alternatives, SPP would be expressed as:

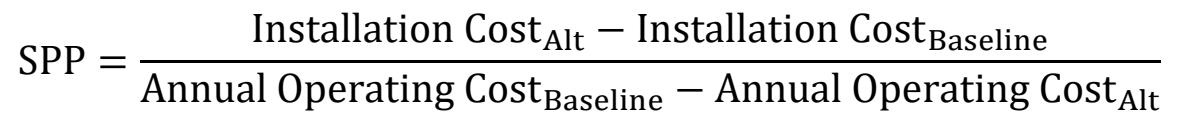

When comparing two design alternatives, this formulation assumes that the initial cost of the alternative design is greater than that of the baseline design, but the annual operating costs are less. If the latter assumption is violated, SPP does not apply. If only the former assumption is violated, then the SPP is zero (i.e., the alternative design has "paid for itself" prior to beginning operation).

The disadvantage of SPP is that it does not account for interest, inflation, or the timing of cash flows - that is, it does not consider the time value of money (Flanagan et al. 1989; Öberg 2005; Schade 2007). Nevertheless, SPP is a widely used metric, and we include it for completeness. Discounted versions of the payback period are also possible (Short, Packey, and Holt 1995; Schade 2007). However, NPV is a better metric for comparison of alternative designs; see Section 3.1. 


\section{Resiliency, Redundancy, Reliability}

Lack of system reliability adds cost and creates expense as a function of downtime (or expected downtime), i.e., system outages. Resilient or redundant design features reduce costs to the extent that they prevent or mitigate downtime resulting from system outages. Successful direct modeling of the anticipated costs associated with reliability (or, more specifically, the lack thereof) requires two elements:

1. The capability to estimate or predict system outages

2. Estimation methods to assign cost to outages (known as "value of lost load" [VoLL]).

The first difficulty is that presently available methods and algorithms for building electrical distribution analysis are not designed to predict system reliability. In the research literature, discussion of AC vs. DC distribution system reliability is limited to qualitative analysis and is somewhat speculative. DC converters and systems are noted to have fewer component counts compared to AC converters and systems, and are therefore predicted to be more reliable (George 2006; Vossos et al. 2020). Although many domain experts consider improved reliability a key feature of DC distribution systems (Marchionini and Zheng 2018), data centers are the only systems known to the authors for which quantitative theoretical and experimental DC vs. AC reliability studies have been published (Sithimolada and Sauer 2010; AlLee and Tschudi 2012). Regardless of the use of AC or DC distribution, data centers are designed for very high reliability, and outage rates are extremely low.

Second, there exists at present no widely accepted standard calculation method for VoLL. Within the electric power industry, IEEE Standard 1366 (IEEE Power \& Energy Society 2012) provides standard, well-known definitions for reliability indices in distribution systems, including the System Average Interruption Frequency Index (SAIFI), System Average Interruption Duration Index (SAIDI), and Customer Average Interruption Duration Index (CAIDI). While useful as systematic quantitative measures of reliability, these indices do not directly quantify the lost value (i.e., customer cost) associated with service interruptions. This shortcoming is acknowledged in the standard, which states, "Unfortunately, the customer cost of unreliability has so far proven impossible to estimate accurately" (IEEE Power \& Energy Society 2012, 24).

The cost of adding resiliency is easy to calculate; the Section 2 equations applied to the resilient design can quantify the additional cost. However, whether the additional system cost would add sufficient value in avoiding lost load is not as well understood, especially given that VoLL depends strongly on circumstances, goals, and user perspectives (Anderson et al. 2020). Further, it is difficult to assess the VoLL for a building system, because VoLL is often defined as a static $\$ / \mathrm{kWh}$ value. This approach works well when the system being evaluated involves energy generation because the additional cost to add the resiliency can be normalized using the metrics to obtain a $\$ / \mathrm{kWh}$ additional cost. However, building electrical distribution system designs on their own do not include on-demand generation. Evaluating this benefit in the context of a building electrical distribution system then either requires a local component failure (outage) model under the assumption that the grid is always available or enhancing the design to include local generation while also considering the potential for grid outages. 
In theory, a VoLL metric for a building could be developed. The all-in LCC or cash flow model of the building (for all systems and activities, not only the electrical distribution system) could be used to determine the value of the building per unit of time. Therefore, given an outage of a specific length of time, the cost could be computed to be the time the building was out of service. The cost of the mitigation system could then be compared. However, obtaining a quantitative estimate would still require an outage model as described previously, and the metric would still strongly depend on circumstances, goals, and perspectives.

A more practical way to incorporate reliability into the cost model is to ensure that the systems being considered have comparable reliability and meet the end user's reliability requirements. This is consistent with current design practice, in which requirements are defined up front to ensure a minimum level of system reliability and therefore mitigate the risk of system failure (Bern Gallagher and Sandra Vanderstoep 2020). (This approach avoids the need to explicitly value anticipated outages.) Organizations such as the Uptime Institute ${ }^{5}$ produce reliability standards and requirements that can be used as a guide to determine if the design alternatives under consideration achieve equivalent reliability.

In summary, it is theoretically possible to analyze costs associated with system reliability, but the presently available modeling tools for building electrical distribution systems do not readily support a direct reliability cost analysis. Given increasing interest in microgrids (AC or DC) with the capability of riding through utility outages and natural disasters, we recommend future work to quantify and value the reliability of building electrical distribution systems. In the meantime, cost modelers should ensure that the systems to be compared achieve comparable reliability.

${ }^{5}$ https://uptimeinstitute.com/ 


\section{Discussion}

Cost analysis of electrical distribution system design alternatives should not be performed in a vacuum. This section discusses several intangible or difficult to quantify aspects of electrical distribution system cost evaluation.

\subsection{Financing}

The proposed cost model excludes revenues or project financing. However, a complete comparison of design alternatives may require considering project financing. For example, certain distribution system designs may enjoy tax breaks, subsidized interest rates, or other incentives from utilities or local, state, and federal governments. (For example, municipalities may provide incentives for projects that integrate renewable energy or provide onsite backup power that mitigates risk during natural disasters.)

\subsection{Cost Drivers}

Some cost drivers are not immediately apparent but can have a large impact. Cost modelers should consider the following potential cost drivers:

- Space Constraints: Many buildings have limited area available for infrastructure. Designing within space constraints may require upgrading to premium hardware with a compact design but a large cost. Space constraints may also preclude certain designs or require the cost modeler to include the cost of expanding the building to accommodate the system footprint.

- Changing or Eliminating the Utility Relationship: Typically, alternative system designs would be compared under the same utility energy rate structure. However, if energy storage is part of the design, it may be possible to change to a different utility rate structure that offers a lower operating cost. If the design offers full microgrid capability with sufficient backup energy sources (e.g., diesel generators, natural gas generators, or fuel cells), it may be possible to eliminate the electric utility interconnection entirely. (Evaluating a complete microgrid solution requires expanding the cost model beyond the categories provided in this report.) Tools such as REopt (NREL 2020) can help a cost modeler determine the cost optimal utility rate structure for any given design.

- Safety Enhancements: Some distribution system technologies offer safety advantages that may reduce or eliminate the need for protective equipment such as conduit and circuit breakers (with commensurate reduction in cost). For example, systems that operate at "touch-safe" voltages (for example, $24 \mathrm{~V}$ ) often do not require cabling to be installed in conduit. DC distribution system technologies that perform current limiting via power electronics also reduce the number of circuit breakers that must be installed.

- Compatibility with Future Technology: DC distribution technology is evolving rapidly. Some desirable features or components are not yet commercially available, such as DCinput VFDs. If the designer anticipates modifications to the distribution system to support future technologies, they should consider the likely cost as part of the overall cost evaluation. For example, suppose that due to technology availability the heating, ventilation, and air conditioning (HVAC) units in a building must initially be ACconnected, however, highly efficient DC-connected units are anticipated to be available within a decade. The designer might consider a higher cost design that provides DC 
distribution to the HVAC units with localized inverters to provide AC electricity to each unit, anticipating that a future upgrade to DC-connected HVAC could then be done at minimal cost. (Upgrading to DC-connected units would require only removing the localized inverters rather than replacing an entire conventional AC distribution system.) 


\section{OpenStudio Integration Plan}

The Energy Design and Scoping Tool for DC Distribution Systems project recommends incorporation of the cost analysis framework proposed in this report into the OpenStudio Analysis Framework (OSAF) (Ball et al. 2020). OSAF already supports large-scale building energy modeling analysis and optimization for EnergyPlus, and support for Modelica models is on the OpenStudio roadmap. The anticipated outcome of the Energy Design and Scoping Tool for DC Distribution Systems project is a harmonic power flow (HPF) library for Modelica that will simulate building electrical distribution system performance and efficiency, including AC, DC, and hybrid distribution designs.

The envisioned analysis cost workflow for building electrical distribution systems (Figure 3 ) is compatible in principle with OSAF. The cost models and metrics described in Sections 2-3 can be implemented as OpenStudio Measures. OpenStudio Measures are model articulation scripts with a standard structure that allow rapid construction and manipulation of building energy models with OSAF (Roth, Goldwasser, and Parker 2016). Measures provide a flexible, replicable, and distributable way to apply the same design modifications or analyses to multiple models, reducing the need for bespoke calculations. OpenStudio Measures to implement the proposed workflow would use input variables to capture the cost parameters described in the cost model (Section 2), whether as static values or as probability distributions. Although the cost formulas proposed in this report are specific to building electrical distribution systems, we recommend generalizing the developed Measures to support arbitrary system types. The developed Measures should support the general cost categories of Figure 1 and enable casespecific computation of costs for different system types. 


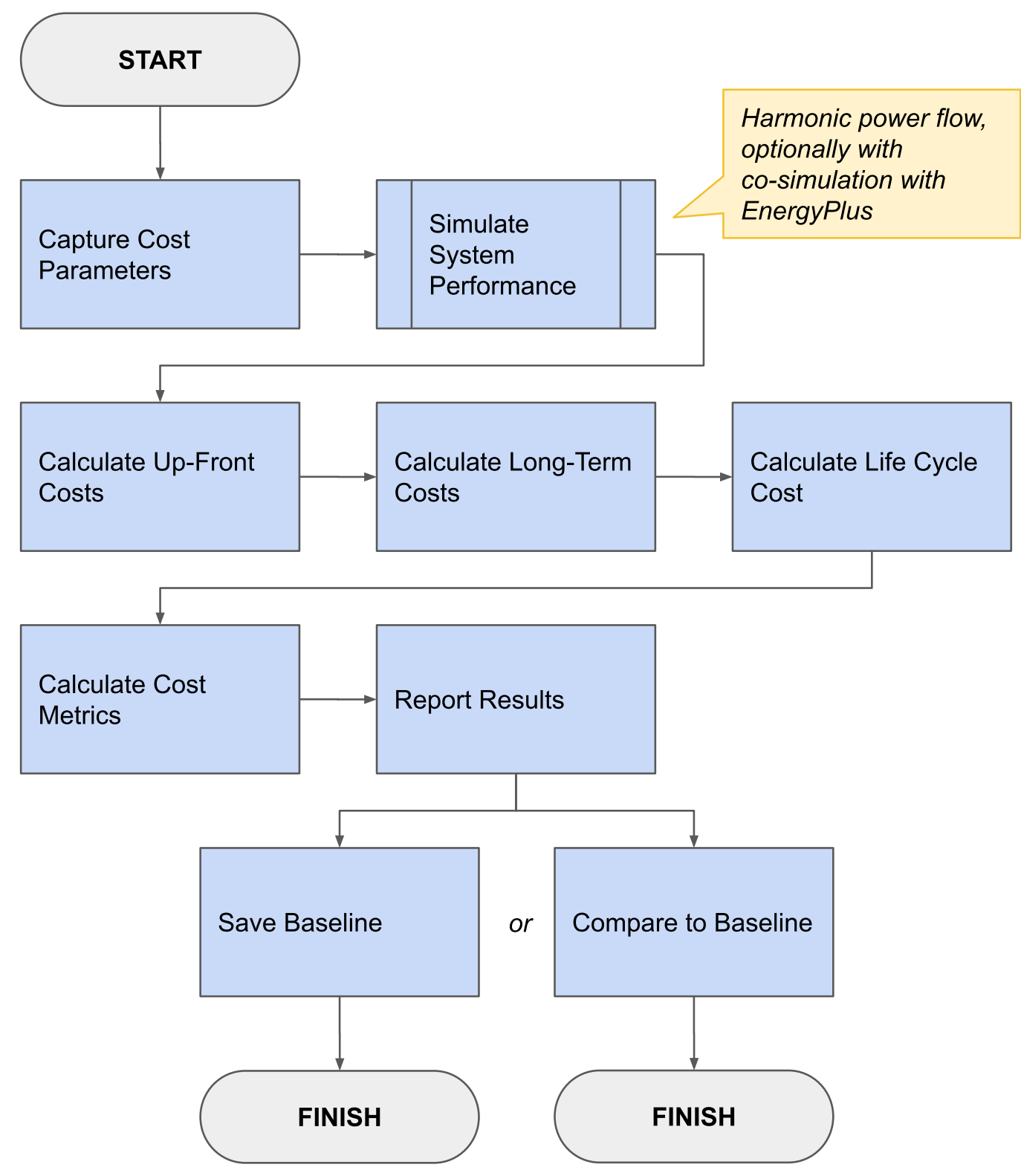

Figure 3. Proposed cost analysis workflow

The full simulation workflow for the Energy Design and Scoping Tool for DC Distribution Systems will require additional development of OSAF to support co-simulation between EnergyPlus and Modelica (Figure 4) based on PyFMI (Andersson, Åkesson, and Führer 2016) or a similar co-simulation approach. While the OpenStudio/EnergyPlus portion can rely on the existing OpenStudio Measure workflow to do the necessary calculations between the simulation provided data and the user provided data, the Modelica workflow for electrical network simulation via the HPF library is not yet developed. 


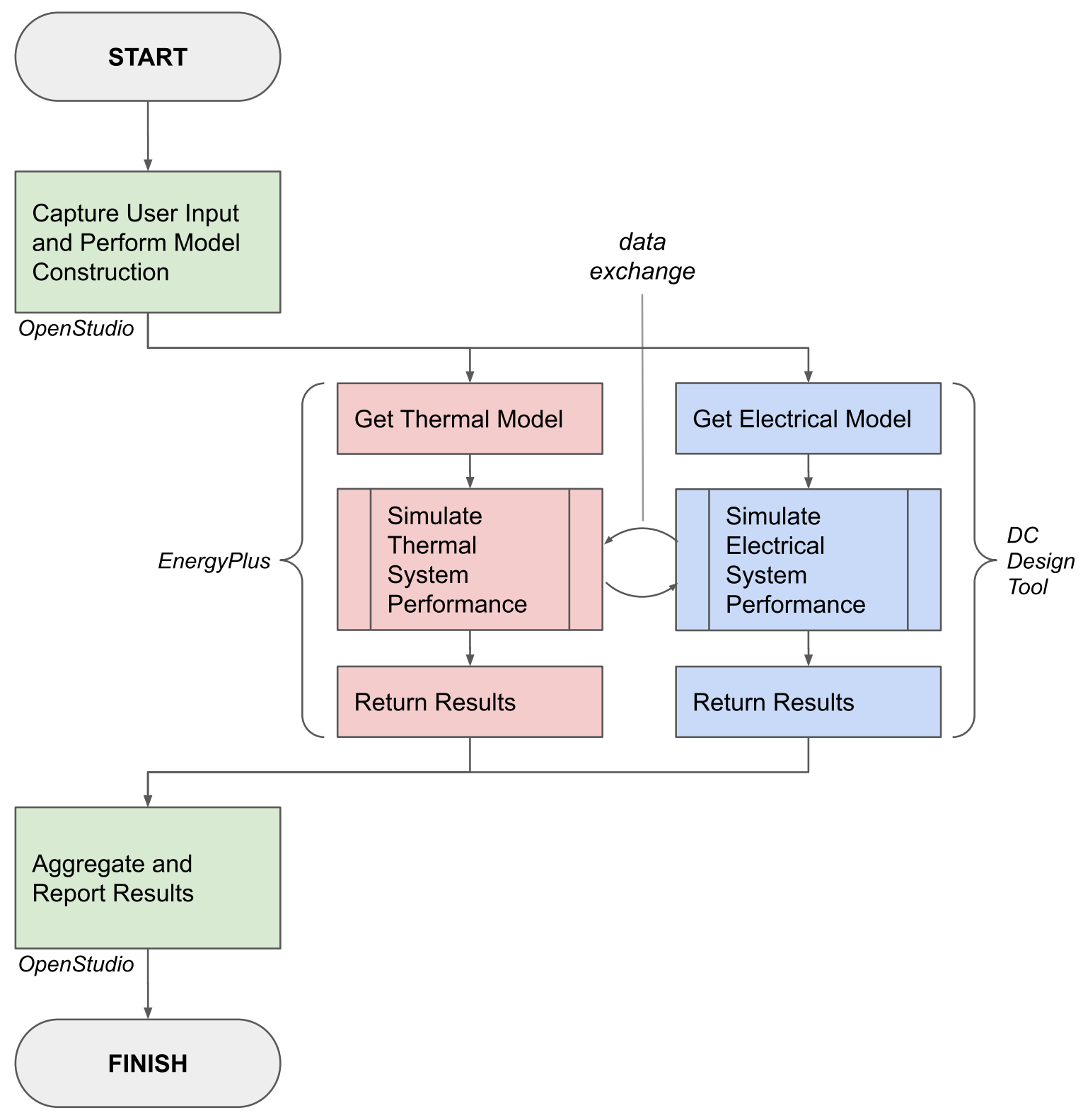

Figure 4. Co-simulation workflow for Energy Design and Scoping Tool for DC Distribution

Specifically, the co-simulation workflow of Figure 4 will require:

1. Parameter Capture: Define and implement methods for capturing cost parameters as cost analysis measure inputs. Similar standards will be needed for capturing design parameters for the HPF electrical network models.

2. Modelica Measures: Define and create a Measure class that will articulate (i.e., create or modify) Modelica models programmatically in a way that is compatible with the OpenStudio Workflow gem (see Ball et al. 2020). Modify the OpenStudio Workflow gem to be compatible with the new Measure class and adapt the HPF library for compatibility with the new Measure class. 
3. Modelica Simulation Outputs: Identify and create standards/methods in Modelica to define and report necessary simulated data as output variables. These methods should be consistent between the Spawn of EnergyPlus (see Wetter et al. 2015) and HPF Modelica libraries as well as consistent with industry standards. The methods must support the export of time series data for postprocessing, e.g., by reporting Measures that calculate utility costs. Defining a standard output file format is part of this task, as is adapting the HPF library to support the correct output format.

4. Modelica Reporting Measures: Define and create a reporting Measure class that will run in OSAF and process the output file defined in Task 3 above. Modify the OpenStudio Workflow gem to be compatible with the new Measure class.

We recommend implementing these tasks as part of a broader initiative to incorporate Modelica models into OSAF, as discussed by Ball et al. (2020). In addition, incorporation of a standard approach for cost evaluation into OSAF will benefit many aspects of building energy modeling, not only analysis of building electrical distribution system designs. 


\section{Conclusions and Future Work}

The cost analysis framework proposed in this report provides a general, extensible structure for cost analysis and comparison for building electrical distribution systems, including AC, DC, and hybrid designs. The framework provides general cost formulas for all cost categories except for reliability costs. The cost formulas are compatible with large-scale analyses, such as the OpenStudio Analysis Framework used for building energy modeling. The proposed formulas and metrics encompass the major cost categories and analysis methodologies proposed in the research literature to date and will provide a consistent framework for future research.

However, significant work remains before the proposed cost framework can be leveraged consistently by building electrical distribution design professionals. Two categories of barriers remain: (1) lack of integration of the proposed framework into standard building energy modeling workflows and, (2) lack of high-quality data to inform and populate cost models. To address the first barrier, we recommend future work to integrate the proposed cost analysis framework into OpenStudio, as described in Section 6. To address the latter, we recommend future research in the following topic areas:

- Quantification of soft costs for building electrical distribution system design, with an emphasis on quantifying cost premiums associated with novel or under-deployed technologies.

- Development and validation of cost estimation formulas for individual distribution components (e.g., transformers, power electronics converters) that provide pricing and installation labor costs as a function of power rating.

- Standardized methods for rapid estimation of wiring/cabling requirements for building electrical distribution systems based on high-level data, such as building total floor area and number of floors.

- Detailed estimation of O\&M costs for building electrical distribution systems, including quantification of O\&M cost differences for $\mathrm{AC}$ and $\mathrm{DC}$ distribution system design alternatives.

- Modeling techniques for predicting the reliability of building electrical distribution systems, including prediction of the frequency and duration of system outages based on design and hardware characteristics.

- Strategies and techniques for valuation of "lost load," i.e., customer costs associated with electrical outages, as discussed in detail in Section 4.

- Identifying and mapping sources of cost data for populating distribution system cost models. 


\section{References}

AlLee, G., and W. Tschudi. 2012. "Edison Redux: 380 Vdc Brings Reliability and Efficiency to Sustainable Data Centers." IEEE Power and Energy Magazine 10 (6): 50-59. https://doi.org/10.1109/MPE.2012.2212607.

Anderson, Kate, Xiangkun Li, Sourabh Dalvi, Sean Ericson, Clayton Barrows, Caitlin Murphy, and Eliza Hotchkiss. 2020. "Integrating the Value of Electricity Resilience in Energy Planning and Operations Decisions." IEEE Systems Journal, 1-11. https://doi.org/10.1109/JSYST.2019.2961298.

Andersson, Christian, Johan Åkesson, and Claus Führer. 2016. "PyFMI: A Python Package for Simulation of Coupled Dynamic Models with the Functional Mock-up Interface." Technical Report. Lund, Sweden: Centre for Mathematical Sciences, Lund University.

Backhaus, Scott, Gregory W. Swift, Spyridon Chatzivasileiadis, William Tschudi, Steven Glover, Michael Starke, Jianhui Wang, Meng Yue, and Donald Hammerstrom. 2015. "DC Microgrids Scoping Study—Estimate of Technical and Economic Benefits." LAUR-15-22097. Los Alamos National Laboratory. http://www.energy.gov/sites/prod/files/2015/03/f20/DC_Microgrid_Scoping_Study_Los Alamos-Mar2015.pdf.

Ball, Brian L., Nicholas Long, Katherine Fleming, Chris Balbach, and Phylroy Lopez. 2020. "An Open Source Analysis Framework for Large-Scale Building Energy Modeling.” Journal of Building Performance Simulation 13 (5): 487-500. https://doi.org/10.1080/19401493.2020.1778788.

Bern Gallagher and Sandra Vanderstoep. 2020. Personal Communication.

Bernal, Willy, Omkar Ghatpande, Avijit Saha, Daniel Gerber, Vagelis Vossos, Bruce Nordman, and Richard Brown. 2021. "Performance Metrics and Methods for Evaluating BuildingLevel Electrical Distribution Systems." Technical Report (Draft). Golden, CO: National Renewable Energy Laboratory. To be published.

Best, K. H., and G. P. Meanley. 1985. "Does Professional Competition Benefit Society?" Proceedings of the Institution of Civil Engineers 78 (3): 588-91. https://doi.org/10.1680/iicep.1985.874.

Biolek, Vojtěch, and Tomáš Hanák. 2019. "LCC Estimation Model: A Construction Material Perspective." Buildings 9 (8): 182. https://doi.org/10.3390/buildings9080182.

Boroyevich, D., I. Cvetković, D. Dong, R. Burgos, F. Wang, and F. Lee. 2010. "Future Electronic Power Distribution Systems a Contemplative View." In 2010 12th International Conference on Optimization of Electrical and Electronic Equipment, 136980. https://doi.org/10.1109/OPTIM.2010.5510477.

Del Pico, Wayne J. 2015. Electrical Estimating Methods. Fourth edition. Hoboken, New Jersey: RS Means, Wiley.

EnergyPlus Development Team. 2020. EnergyPlus (version 9.4.0). U.S. Department of Energy. https://www.energyplus.net/.

Federal Energy Management Program. 2020. Energy Escalation Rate Calculator (version 2.0.20). Windows. U.S. Department of Energy.

https://www.energy.gov/eere/femp/building-life-cycle-cost-programs.

Flanagan, R., G. Norman, J. Meadows, and G. Robinson. 1989. Life Cycle Costing: Theory and Practice. Oxford: BSP Professional Books.

Freeman, Janine M., Nicholas A. DiOrio, Nathan J. Blair, Ty W. Neises, Michael J. Wagner, Paul Gilman, and Steven Janzou. 2018. "System Advisor Model (SAM) General 
Description (Version 2017.9.5).” Technical Report NREL/TP-6A20-70414. Golden, CO: National Renewable Energy Laboratory. https://doi.org/10.2172/1440404.

Fregosi, D., S. Ravula, D. Brhlik, J. Saussele, S. Frank, E. Bonnema, J. Scheib, and E. Wilson. 2015. "A Comparative Study of DC and AC Microgrids in Commercial Buildings across Different Climates and Operating Profiles." In 2015 IEEE First International Conference on DC Microgrids (ICDCM), 159-64. https://doi.org/10.1109/ICDCM.2015.7152031.

Fu, Ran, David Feldman, and Robert Margolis. 2018. "U.S. Solar Photovoltaic System Cost Benchmark: Q1 2018.” Technical Report NREL/TP-6A20-72399. Golden, CO: National Renewable Energy Laboratory. https://www.nrel.gov/docs/fy19osti/72399.pdf.

Gal, Itai, Brent Lipson, Trina Larsen, Ark Tsisserev, and Julian Mereuta. 2019. "DC Microgrids in Buildings." Technical Report. Toronto, ON, Canada: CSA Group.

Garbesi, Karina, Vagelis Vossos, and Hongxia Shen. 2011. "Catalog of DC Appliances and Power Systems.” LBNL-5364E. Berkeley, CA: Lawrence Berkeley National Laboratory. https://etapublications.lbl.gov/sites/default/files/catalog_of dc appliances and power_systems $1 \mathrm{~b}$ nl-5364e.pdf

George, Karen. 2006. "DC Power Production, Delivery, and Utilization.” White Paper. Electric Power Research Institute. http://mydocs.epri.com/docs/CorporateDocuments/WhitePapers/EPRI_DCpower_June20 06.pdf.

Gerber, Daniel L., Vagelis Vossos, Wei Feng, Chris Marnay, Bruce Nordman, and Richard Brown. 2018. "A Simulation-Based Efficiency Comparison of AC and DC Power Distribution Networks in Commercial Buildings.” Applied Energy 210 (January): 116787. https://doi.org/10.1016/j.apenergy.2017.05.179.

Glasgo, Brock, Inês Lima Azevedo, and Chris Hendrickson. 2016. "How Much Electricity Can We Save by Using Direct Current Circuits in Homes? Understanding the Potential for Electricity Savings and Assessing Feasibility of a Transition towards DC Powered Buildings." Applied Energy 180 (October): 66-75. https://doi.org/10.1016/j.apenergy.2016.07.036.

IEEE Power \& Energy Society. 2012. "IEEE Guide for Electric Power Distribution Reliability Indices.” Standard 1366-2012. New York, NY: IEEE. https://doi.org/10.1109/IEEESTD.2012.6209381.

International Electrotechnical Commission. 2017. "LVDC: Electricity for the 21st Century." Technology Report LVDC:2017-09(en). Geneva, Switzerland: International Electrotechnical Commission. https://basecamp.iec.ch/download/iec-technology-reportlvdc-electricity-for-the-21st-century-en/.

Kishk, Mohammed, Assem Al-Hajj, Robert Pollock, Ghassan Aouad, Nick Bakis, and Ming Sun. 2003. "Whole Life Costing in Construction: A State of the Art Review." In The RICS Foundation Paper Series. Vol. 4. 18. Salford, United Kingdom: RICS Foundation.

Law, Jonathan, and John Smullen, eds. 2008. A Dictionary of Finance and Banking. 4. ed. Oxford Paperback Reference. Oxford: Oxford Univ. Press.

Marchionini, Brian, and Shuyu Zheng. 2018. "Direct Current in Buildings: A Look at Current and Future Trends." Technical Report NEMA DCP 1-2018. National Electrical Manufacturers Association. https://www.nema.org/docs/default-source/standardsdocument-library/nema-dcp-1-2018-watermarked.pdf. 
McGeorge, John F. 1988. "Design Productivity: A Quality Problem." Journal of Management in Engineering 4 (4): 350-62. https://doi.org/10.1061/(ASCE)9742-597X(1988)4:4(350).

NREL. 2020. “REopt: REnewable Energy Integration \& Optimization.” REopt Lite. 2020. https://reopt.nrel.gov/.

Öberg, Mats. 2005. "Integrated Life Cycle Design - Applied to Concrete Multi-Dwelling Buildings.” Report TVBM. PhD Thesis, Lund, Sweden: Lund University.

OpenEI. 2020. "Utility Rate Database.” Open Energy Information. February 11, 2020. https://openei.org/wiki/Utility_Rate_Database.

OpenStudio Development Team. 2020. OpenStudio (version 3.0.1). U.S. Department of Energy. https://www.openstudio.net/.

O’Shaughnessy, Eric, Gregory F. Nemet, Jacquelyn Pless, and Robert Margolis. 2019. "Addressing the Soft Cost Challenge in U.S. Small-Scale Solar PV System Pricing." Energy Policy 134 (November): 110956. https://doi.org/10.1016/j.enpol.2019.110956.

Prabhala, Venkata Anand, Bhanu Prashant Baddipadiga, Poria Fajri, and Mehdi Ferdowsi. 2018. "An Overview of Direct Current Distribution System Architectures \& Benefits." Energies 11 (9): 2463. https://doi.org/10.3390/en11092463.

Pratt, A., P. Kumar, and T. V. Aldridge. 2007. "Evaluation of 400V DC Distribution in Telco and Data Centers to Improve Energy Efficiency." In INTELEC 07 - 29th International Telecommunications Energy Conference, 32-39. https://doi.org/10.1109/INTLEC.2007.4448733.

Roth, Amir, David Goldwasser, and Andrew Parker. 2016. "There's a Measure for That!" Energy and Buildings 117 (April): 321-31. https://doi.org/10.1016/j.enbuild.2015.09.056.

RSMeans Data. 2018. Building Construction Costs with RSMeans Data, 2019. Edited by Robert W Mewis. 77th ed. Rockland, MA: Gordian.

Sannino, A., G. Postiglione, and M. H. J. Bollen. 2003. "Feasibility of a DC Network for Commercial Facilities." IEEE Transactions on Industry Applications 39 (5): 1499-1507. https://doi.org/10.1109/TIA.2003.816517.

Santos, Arthur, James Cale, Avpreet Othee, Daniel Gerber, Stephen Frank, Gerald Duggan, Dan Zimmerle, and Richard Brown. 2019. "Comparison of Load Models for Estimating Electrical Efficiency in DC Microgrids.” In Proceedings of the 3rd IEEE International Conference on DC Microgrids. Matsue, Japan.

Savage, Paul, Robert R. Nordhaus, and Sean P. Jamieson. 2010. "DC Microgrids: Benefits and Barriers." In From Silos to Systems: Issues in Clean Energy \& Climate Change. Yale School of Forestry \& Environmental Studies.

Schade, Jutta. 2007. "Life Cycle Cost Calculation Models for Buildings." In Proceedings of 4th Nordic Conference on Construction Economics and Organisation : Development Processes in Construction Management, 321-29. Forskningsrapport / Luleå Tekniska Universitet. Luleå University of Technology, Structural and Construction Engineering.

Short, Walter, Daniel J. Packey, and Thomas Holt. 1995. "A Manual for the Economic Evaluation of Energy Efficiency and Renewable Energy Technologies.” Technical Report NREL/TP-462-5173. Golden, CO: National Renewable Energy Laboratory. https://doi.org/10.2172/35391.

Sithimolada, V., and P. W. Sauer. 2010. "Facility-Level DC vs. Typical AC Distribution for Data Centers: A Comparative Reliability Study." In TENCON 2010 - 2010 IEEE Region 10 Conference, 2102-7. https://doi.org/10.1109/TENCON.2010.5686625. 
Solar Energy Industries Association, and Wood Mackenzie. 2020. "U.S. Solar Market Insight: 2020 Q3.” Market Report. Wood Mackenzie Power \& Renewables. https://www.seia.org/us-solar-market-insight.

Thomas, Brinda A., Inês L. Azevedo, and Granger Morgan. 2012. "Edison Revisited: Should We Use DC Circuits for Lighting in Commercial Buildings?” Energy Policy 45 (June): 399411. https://doi.org/10.1016/j.enpol.2012.02.048.

U.S. Bureau of Labor Statistics. 2020. "Occupational Outlook Handbook.” U.S. Bureau of Labor Statistics. 2020. https://www.bls.gov/ooh/.

Vossos, Vagelis, Melanie Gaillet-Tournier, Daniel Gerber, Bruce Nordman, Richard Brown, Willy Bernal, Omkar Ghatpande, Avijit Saha, Deru, Michael, and Frank, Stephen. 2020. "Direct-DC Power in Buildings: Identifying the Best Applications Today for Tomorrow's Building Sector.” In ACEEE Summer Study on Energy Efficiency in Buildings, 15. ACEEE. https://aceee2020.conferencespot.org/eventdata/pdf/catalyst activity 10941/catalyst_activity_paper_20200812133207826 91c896d 8 916c 4281 85c5 806c6a972115.

Vossos, Vagelis, Karina Garbesi, and Hongxia Shen. 2014. "Energy Savings from Direct-DC in U.S. Residential Buildings." Energy and Buildings 68 (January): 223-31. https://doi.org/10.1016/j.enbuild.2013.09.009.

Vossos, Vagelis, Daniel Gerber, Youness Bennani, Richard Brown, and Chris Marnay. 2018. "Techno-Economic Analysis of DC Power Distribution in Commercial Buildings." Applied Energy 230 (November): 663-78. https://doi.org/10.1016/j.apenergy.2018.08.069.

Vossos, Vagelis, Karl Johnson, Margarita Kloss, Ruby Heard, Daniel Gerber, Bruce Nordman, Eric Mannarino, Mukesh Khattar, and Richard Brown. 2019. "Direct Current as an Integrating and Enabling Platform for Zero-Net Energy Buildings.” CEC-500-2019-038. California Energy Commission. https://eta.lbl.gov/publications/direct-current-integratingenabling.

Waters, Clarence E., Luigi Gentile Polese, Mahmoud Alahmad, Stephen Frank, and Lee Keun. 2014. "Electrical Distribution Systems for Commercial Reference Building Models." Journal of Architectural Engineering 20 (1): 04013005. https://doi.org/10.1061/(ASCE)AE.1943-5568.0000125.

Wetter, Michael, Thierry Nouidui, David Lorenzetti, Edward A. Lee, and Amir Roth. 2015. "Prototyping the Next Generation EnergyPlus Simulation Engine." In Proceedings of the 14th International Conference of the International Building Performance Simulation Association (BS2015), 403-10. Hyderabad, India. https://simulationresearch.lbl.gov/wetter/download/2015-ibpsa-p2419.pdf. 